\section{Veinte años después}

ALBeRTo LóPEZ MULLOR ${ }^{1}$

Servicio de Patrimonio Arquitectónico local. Diputación de Barcelona

\section{Resumen}

En este trabajo se presenta un balance de las investigaciones arqueológicas realizadas en el patrimonio edificado en los últimos veinte años por el Servicio de Patrimonio Arquitectónico Local de la Diputación de Barcelona. Se analizan los instrumentos y criterios de intervención que se han seguido, señalando algunos de los principales edificios que han sido analizados. Por último se expican brevemente, como ejemplos significativos, las intervenciones llevadas a cabo en la iglesia de San Quirze de Pedret (Cercs) y en la Casa parroquial de Sant Andreu de Castellnou de Bages, convertida en cementerio tras su restauración.

Palabras claves: Patrimonio Arquitectónico, Restauración, Investigación Arqueológica.

\section{Abstract}

In this work we present a summary of the archaeological investigations undertaken in the last twenty years on architectural heritage by the Service of Local Archaeological Heritage of the Diputación of Barcelona. We analyze both the instruments and the intervention criteria which have been followed, pointing out some of the main buildings being analyzed. Finally, we briefly explain, as meaningful examples, the interventions carried about in the church of San Quirze de Pedret (Cercs) and at the parish house of Sant Andreu de Castellnou de Bages, turned into a graveyard after its restoration.
}

Key words: Architectural heritage, Restoration, Archaeological investigation.

\section{ANTECEDENTES}

A nuestro modo de ver, la arqueol ogía del patrimonio edificado es aquel sistema de investigación histórica que tiene por objeto todos los elementos estratificados en una construcción, y no sólo en su subsuel o. Sin duda, esta clase de estudios no hubieran podido llevarse a cabo sin disponer del método propuesto por E.C. H arris a partir de 1975, que nos indicó cómo poner orden en un registro que, por entonces, ya era estratigráfico, en nuestro caso de acuerdo con las enseñanzas de Lamboglia y sus epígonos, pero que no acababa de aportar toda la objetividad posible en la recogida y la interpretación de los datos de campo.

El Ilamado "método H arris" comenzó a aplicarse en España en 1979. N uestra primera experiencia con tal procedimiento tuvo lugar a finales de aquel mismo año, en la excavación de la ermita de N uestra Señora de Bellvitge (l'H ospital et de Llobregat, Barcelona). En aquella oportunidad, con motivo de una serie de sondeos en una pequeña construcción de origen altomedieval, hasta entonces sólo atisbado a través de las fuentes literarias, pusimos en práctica el método de registro que nos había sido dado a conocer a través del equipo que entonces trabajaba en el Louvre, encabezado por P.J. Trombettaz. La publicación de los trabajos de Bellvitge, posterior en al gunos años a su realización material (LóPEZ MULLOR, 1982, 1988 y 1992), presentaba, por primera vez en la arqueología medieval catal ana, el diagrama estratigráfico el aborado y, a través de los resultados de los sondeos, se proponía la configuración original y posterior evolución del templo.

Muy poco después, en 1980, pusimos en práctica el nuevo modelo de registro en el sondeo "Cisternas 10", en el área septentrional de tabernae del foro de Emporiae (fig. 1), siendo también una de las primeras experiencias de la aplicación de este tipo de registro en el campo de la arqueol ogía clásica, paral el a a la que se ll evaba a cabo en la villa romana de Vilauba (Camós, Girona). ${ }^{3}$ Tras estos dos ensayos, efectuados en yacimientos de muy distinta problemática, envergadura y cronología, pasamos a utilizarlo de manera cotidiana hasta el presente.

\footnotetext{
${ }^{1}$ Servicio de Patrimonio A rquitectónico Local. Diputación de Barcelona. Comte d'U rgell, 187. 08036-Barcelona. E-mail: Iopezmal@diba.es.

${ }^{2}$ Estos investigadores impartieron un seminario en el Museu Arqueològic de Barcelona, en el que participamos X. Aquilué, X. Font, R. M ar, J.A. M uñoz, J. Ruiz de Arbulo, E. Sanmartí y quien suscribe. Sobre los trabajos del Louvre puede verse, por ejemplo: TrombetTA, 1986, 1987.

${ }^{3}$ Ripoll, SAN MARTí, LóPez MulLor, 1982; López Mullor, 1989: 35-45, LóPez MULLOR, 1998. El trabajo de campo en este sondeo sellevó a efecto bajo la dirección técnica del que suscribey la supervisión de Eduard Ripoll Perelló. También tomaron parte en esta excavación $X$ avier Aquilué, $X$ avier Font y J oaquín Ruiz de Arbulo. Sobre la villa de Vilauba, puede verse: Nolla, CASTANyer, Tremoleda, 1992 y Castanyer, Trem Oleda, 1999.
} 


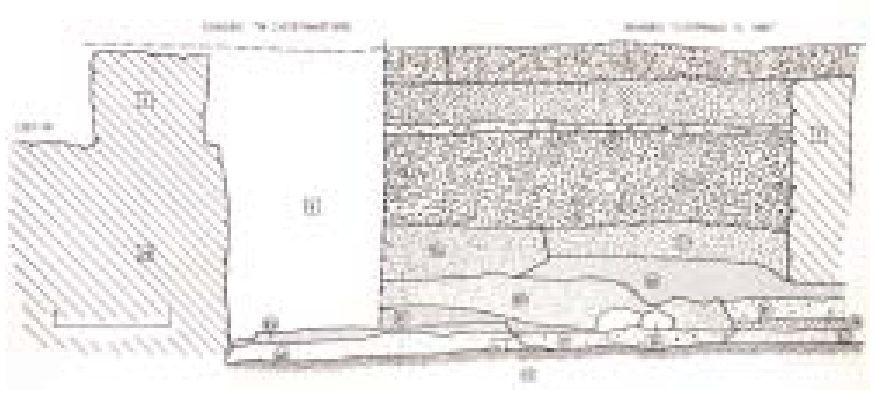

Fig.1. Excavación en el sondeo C 10, al norte del foro de la ciudad romana de Emporiae (I'Escala, Girona), 1980, foto: A. López

Para llevar a cabo estas primeras tentativas metodológicas nos basamos en los principios contenidos en dos trabajos del ya citado E.C. H arris (H ARRIS, 1975, 1977), así como en un pequeño apéndice de 0stia IV , obra de A. Carandini (CARANDINI, 1977), o en un primer artículo de Maetzke y otros (M AEZTKE et alii, 1977). Más tarde, la publicación de ensayos más extensos por parte de los dos primeros autores mencionados (H ARRIS, 1979a, 1979b; CARAN DINI, 1981) provocó una popularización extraordinaria del método, que generó un torrente bibliográfico todavía no agotado, que nos abstendremos de citar.

Desde los inicios de la aplicación del método, tuvimos en gran consideración el estudio de las estructuras arquitectónicas, tanto de las halladas en el subsuel o, como de las aéreas. $Y$ en este camino no fue poca la influencia recibida, tanto de los tratadistas más clásicos, como Lamboglia - otra vez-, cuya obra acerca de la interpretación de vestigios arquitectónicos era entonces de obligada consulta, como de investigadores que empezaban a hollar caminos innovadores a la hora del anál isis de ruinas y edificios, entre los cuales cabe destacar a Luis Caballero, cuyo trabajo sobre Santa M aría de M elque, publicado en 1980 (CABALLERO, 1980), fue para nosotros muy revelador.

En consecuencia, a partir de 1983, al comenzar a dirigir las investigaciones arqueológicas del Servicio de Catalogación y Conservación de Monumentos (hoy de Patrimonio Arquitectónico Local) de la Diputación de Barcelona, la propia índole de los trabajos, enmarcados dentro de los estudios históricos previos a la redacción de los respectivos proyectos de restauración, implicaba que tuviéramos muy presentela consideración de todo el monumento como documento arqueológico, es decir, como yacimiento ${ }^{4}$. En consecuencia, desde las primeras intervenciones, se reforzó y completó el registro, prestándose atención a la excavación en extensión de los yacimientos. A este propósito, es reveladora la marcha de los trabajos en la iglesia de Santa Càndia d'Orpí (1983-1984), el primer lugar que estudiamos para el Servicio de Monumentos, en la que, en principio, se había previsto la realización de algunos sondeos y, a la postre, se excavó todo su espacio interior, parte del entorno inmediato y la cubierta, proporcionando datos que posibilitaron la reconstrucción de su larga evolución histórica y fueron decisivos para la posterior obra de restauración (LóPEZ MULLOR, SUREDA, 1984; LóPez MulLor et alii, 1986; LóPEz MULLOR, Caixal, Fierro, 1989).

El estudio de conjuntos estratificados muy por encima de la cota cero, situados, por ejemplo, en las cubiertas de los edificios, se convirtió en norma general a partir de la experiencia de Santa Càndia, Ilevándose también a cabo, al poco tiempo, en Sant Vicenç de Malla (1983-1984; LóPEZ Mullor, 1984a, 1984b; LóPez MuLlor et alii, 1986 y 1991). Después, se extendió a multitud de lugares. Incluso, en algunos de ellos, como la iglesia parroquial de Santa Eulàlia de Riuprimer (1986-1987)5, este trabajo
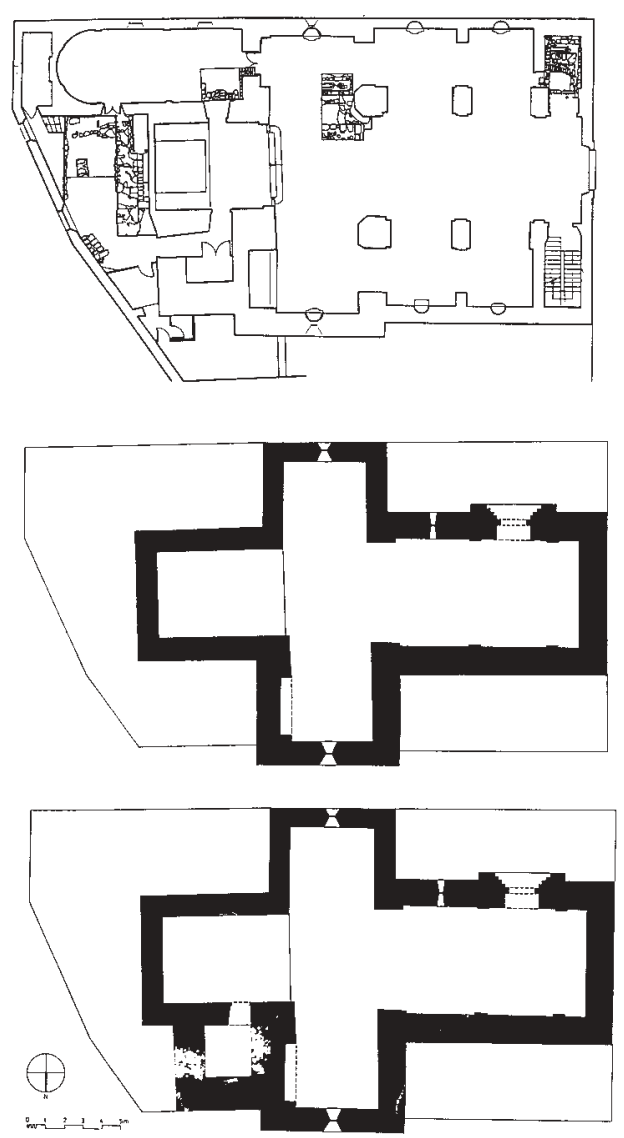

Fig.2. Plantas evolutivas de la iglesia de Santa Eulàlia de Riuprimer (Barcelona)

${ }^{4}$ Sobre estos conceptos, cf. LóPez MuLLOR, 1986 y 1990a.

${ }^{5}$ Esta excavación fue dirigida por X. Fierro y M. Clua. 


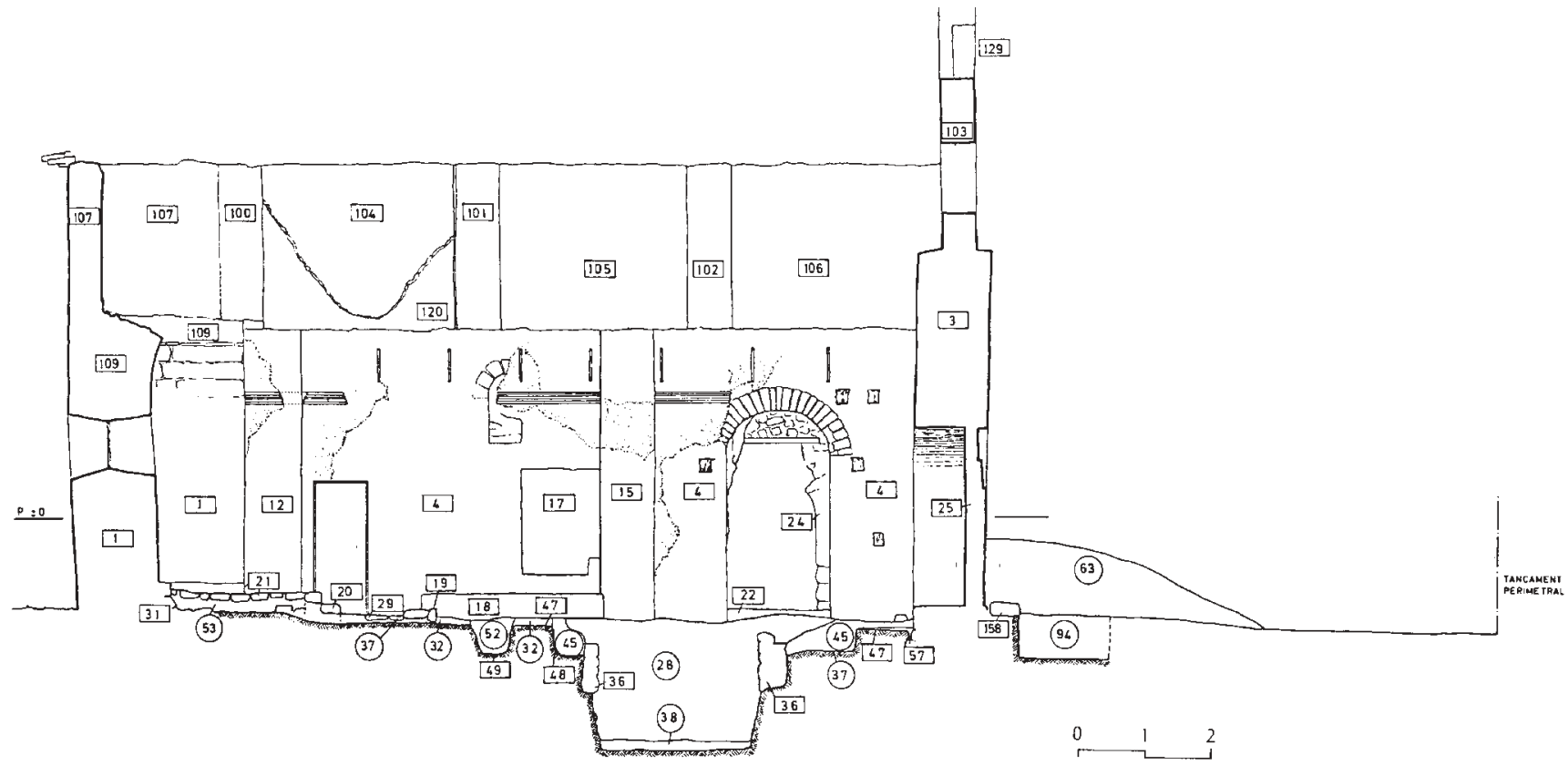

Fig.3. Sección de la iglesia de Sant J aume Sesoliveres (Igualada, Barcelona), excavada en 1993, con indicación de las unidades estratigráficas

constituyó la parte más importante de la intervención arqueológica. Allí, el edificio no debía ser restaurado completamente, ya que la intervención se circunscribía al campanario y la cubierta. El estudio de estos dos ámbitos y al gunas catas estratigráficas en puntos estratégicos de la nave primitiva y la antigua cabecera desvelaron la evolución de un templo, en origen, anterior al románico, reformado en el siglo XI, y cuyo aspecto actual se debe a una intervención neoclásica fechada en 1805 (fig. 2; LóPEZ MULLOR, 1990b; FIERRO, 1991).

H acia la misma época, se empezó a excavar el relleno de bóvedas intermedias, tanto a título de acción exclusiva, como en el claustro Manning de la Casa de Caridad de Barcel ona (1985), donde apareció un magnífico conjunto cerrado de cerámica común vidriada (CAIXAL, FIERro, LóPEZ MULLOR, 1991), como en el marco de investigaciones mucho más amplias. Tal es el caso, por ejemplo, de la basílica de Sant Llorenç prop Bagà, en Guardiola de Berguedà, la excavación de cuyo piso intermedio (19841986) fue decisiva para entender el funcionamiento en época medieval de este interesante edificio (LóPEZ MULLOR, 1995).

Sin embargo, en todos estos lugares, y quizá tal hecho sea el que aquí más interese, se introdujeron y estudiaron dentro de la secuencia arqueol ógica las estructuras aéreas que formaban la construcción o el edificio en que se intervenía. Una sección axial de la iglesia de Sant Bartomeu de $\mathrm{N}$ avarcles, excavada en 1985-1986, que se ha publicado en diversas ocasiones ${ }^{6}$ y otra de la iglesia de Santa M aría de Rubió, excavada en 1986-19877, pueden ser esclarecedoras de este modo de proceder, como también lo son las secciones y al zados de Sant Quirze de Pedret, excavado entre 1989 y 1993, en los que se observa la definición de las distintas unidades estratigráficas murales 0 aéreas y su imbricación en la secuencia general (fig. 11)8.

Una representación más precisa de las diferencias cronológicas y estratigráficas de las diversas partes del edificio queda patente en la publicación de los trabajos en la iglesia de Sant Jaume Sesoliveres, en Igualada (fig. 3), excavada en 1993 (López Mullor, Fierro, CaIXAL, 1993 y 1995), y sobre todo en los planos en color del castillo de Castelldefels (LóPEZ M ULLOR, 2000), y que están en línea con la presentación de resultados que venimos real izando en los últimos tiempos, y que también se ha puesto en práctica en la casa parroquial de Castellnou de Bages (1998), las iglesias de Sant Pere de Serrallonga (Alpens, 1998-1999) y y Sant Sadurní de R otgers (Borredà, 2000) 0 el puente de Pedret (Berga-Cercs, 1999) ${ }^{10}$, según puede verse en las figuras 14-15 y 5 .

\footnotetext{
${ }^{6}$ P.e. en 1991, por À. Caixal y X. Solé, directores de la excavación.

${ }^{7}$ Bajo la dirección de M. Juan.

${ }^{8}$ López MulLor, Gonzáles, 1991; López MulLor, 1995. De este yacimiento nos ocuparemos más adel ante.

${ }^{9}$ Excavada por J. Fierro.

${ }^{10}$ Estos dos yacimientos fueron excavados por J. M. Vila.
} 


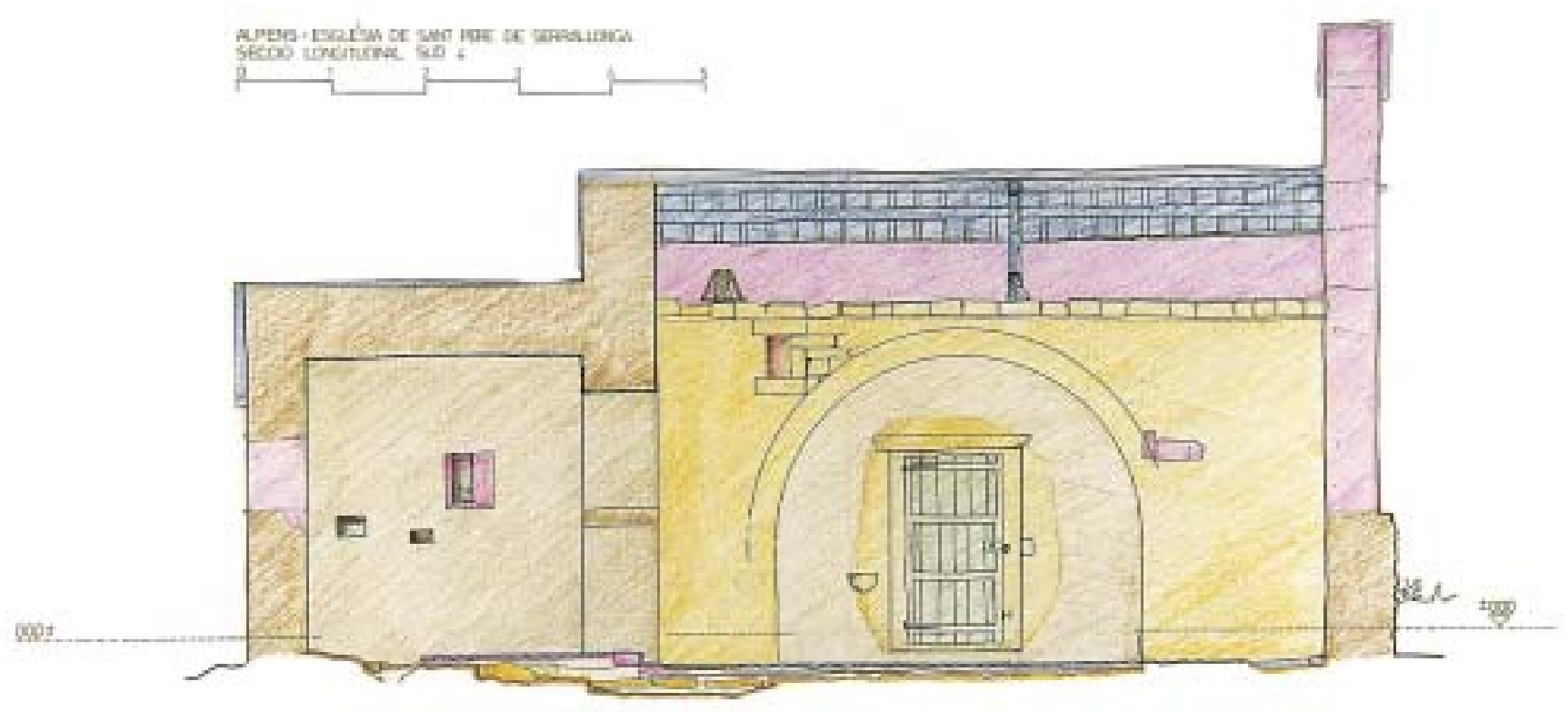

Fig.4. Sección de la iglesia de Sant Pere de Serrallonga (Alpens, Barcelona), excavada en 1998-1999, con indicación de los horizontes cronológicos

Representaciones de este cariz se aproximan más a las popularizadas por R. Parenti (PARENTI, 1985, 1988a y b, 1995) y G.P. Brogiolo (BRoGIOLO, 1988 a y b, 1995) o, en nuestro país, por los equipos formados por $L$. Caballero, $L$. Cámara y P. Latorre (CABALlero, 1980, 1987, 1995; Caballero et alii, 1991-1992; Caballero, Cámara, 1995; Latorre, 1995; Latorre, Caballero, 1995), o bien por A. Azkárate, A. Fernández de Jáuregui y N úñez, entre otros ${ }^{11}$. Sin embargo, la discriminación estratigráfica de las fábricas representadas en al zado no constituye el fin último de nuestros trabajos que se orientan en mayor medida, cuando el yacimiento lo permite, a la recuperación volumétrica de las distintas etapas del edificio. Es el caso, por ejemplo, de las construcciones ibéricas y romanas de Darró en Vilanova i la Geltrú (López Mullor et alii, 1992), de la iglesia de Sant Quirze de Pedret (fig. 6-10), la baślica monacal de Sant Llorenç prop Bagàà ${ }^{12}$ o el conjunto de Castelldefels. En estas ocasiones los datos all egados a partir del análisis de los paramentos han permitido restituciones tridimensionales, que complementan las series de plantas evolutivas, normales como conclusiones de nue-

\footnotetext{
${ }^{11}$ P.e. Azkaráte et alii, 1995. En estas mismas actas se puede ver una copiosa bibliografía sobre los trabajos realizados por el equipo de A. Azkárate, al que recientemente se ha incorporado J.A. Q uirós.

${ }^{12}$ Versión más amplia en LóPEZ MULLOR, 1995.

${ }^{13}$ Cfr. p.e. Sant Jaume Sesoliveres: supra; termas de Sant Boi de Llobregat: LóPEZ MULLOR, EsTANy, 1993; Torre del Baró de Viladecans: LópEz MulLoR et alii, 1998; villa romana y castillo de Cubelles: López MulLor, CAIXAL, FIERRo, 1997 y 1998
}

stros trabaj os sobre patrimonio edificado desde el inicio de la publicación de los mismos en 1984.

Este género de conclusiones permitió disponer de datos precisos para restituir a la iglesia de Pedret su configuración ideal a mediados del siglo X (fig. 7 a 12), y también ha permitido la elaboración del proyecto básico de restauración de Sant Llorenç prop Bagà, en el que se plasma el aspecto del conjunto fundado hacia el 983 en el momento anterior a su deterioro ireversible por parte de un terremoto en 1428.

Cabe decir, sin embargo, que a lo largo de los últimos años hemos venido obviando la difusión de diagramas estratigráficos, que juzgamos más adecuados como instrumentos auxiliares de la labor de gabinete que como ilus-traciones de una publicación, en que las plantas y sobre todo las secciones ya ofrecen información estratigráfica completa y de primera mano. Tampoco creemos necesaria-sobre todo por motivos económicos- la difusión de fichas de unidades estratigráficas (U.E.), aunque en algún caso, atendiendo a la especial complejidad del yacimiento 0 a su singularidad, se hayan incluido en las publicaciones repertorios estratigráficos. Del mismo modo, intentamos presentar secuencias en que las unidades se hallen agrupadas por horizontes cronológicos ${ }^{13}$. Estas estratigrafías simplificadas que suelen complementar a las secciones tradicionales en las que se especifican todas las U.E. descubiertas, expresan períodos cronológicos coherentes, que tienen justa correspondencia en las sucesiones 


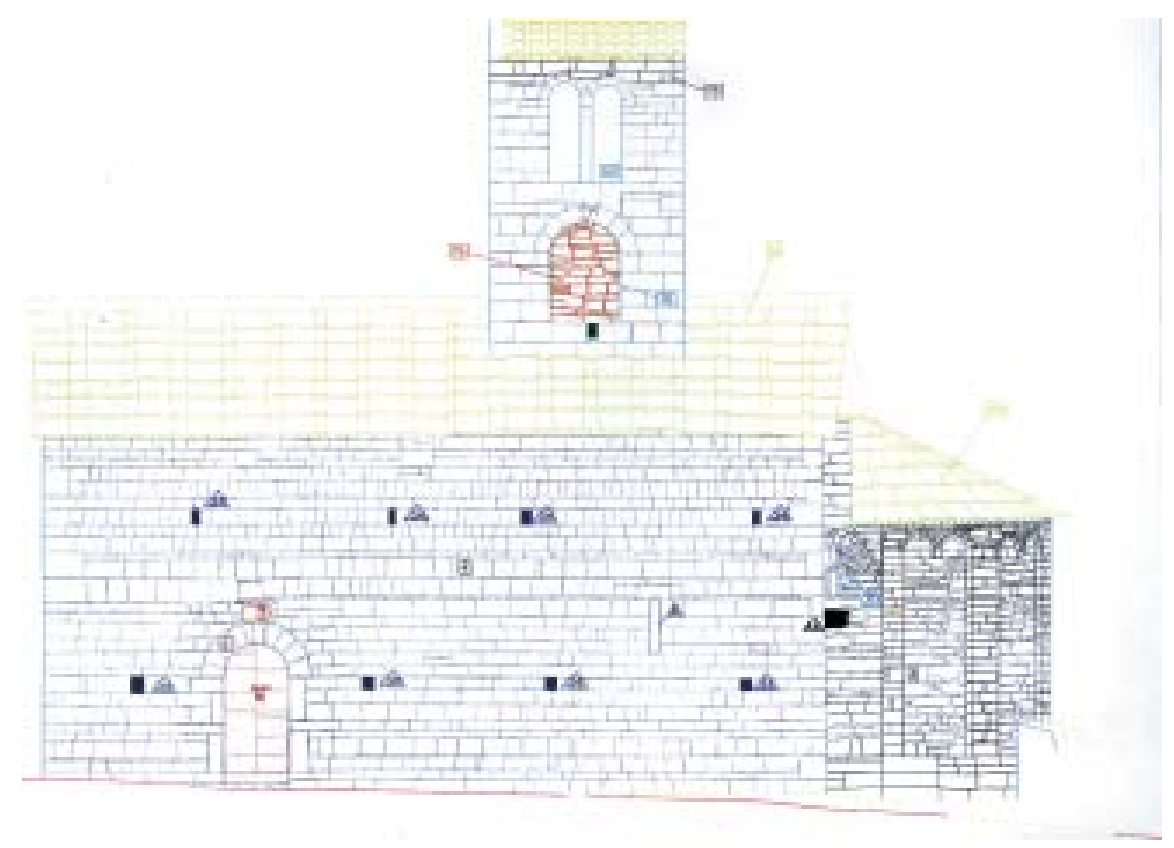

Fig.5. Alzado de la iglesia de Sant Sadurní de Rotgers (Borredà, Barcelona), excavada en 2000, con indicación de los horizontes cronológicos

de plantas y en las respectivas representaciones axonomé tricas.

Llegado el momento de definir esta manera de actuar, podemos concluir que, básicamente, la arqueología del patrimonio edificado lo es cuando su objetivo trasciende los resultados de la excavación y se ocupa también, o solamente, del estudio de las estructuras aéreas a través de la estratificación que presentan. Se trata, pues, de utilizar un método de aproximación al yacimiento que pueda permitir un conocimiento integral del mismo. De esta manera, y entendiendo como yacimiento todo el conjunto edificado, la atención deberá centrarse por igual en acciones arqueológicas consideradas tradicionales, tales como la abertura de sondeos o la excavación de superficies amplias, ya sea por debajo o por encima de la cota 0 , como en el análisis estratigráfico pormenorizado de paramentos y otras estructuras aéreas. Así, las conclusiones del estudio arqueológico atañerán indiscriminadamente a todos los elementos del conjunto construido, visibles o no.

N o querría terminar este preámbulo sin haber hecho hincapié en la gran importancia que tiene en este campo el análisis tipológico. Se trata de una tarea básica en cual-

\footnotetext{
${ }^{14}$ TABALES, 1998. En estas mismas actas se puede ver bibliografía más reciente en la ponencia presentada por este autor.

${ }^{15}$ D urante el Seminario de A rqueol ogía de la A rquitectura cel ebrado los días 1820 de febrero del año 2002 se presentó, además, el estudio sobre el castillo de Castelldefels (LóPEZ MULLOR, 2000).
}

quier clase de investigación arqueológica y aquí no lo es menos. Es evidente que las rel aciones estratigráficas, por sí mismas, sól o proporcionan dataciones relativas, y que, sin el auxilio de sondeos o de la aparición de el ementos datables dentro de los paramentos, es difícil Ilegar a fechas absolutas. N o obstante, las seriaciones tipológicas de fábricas, elementos arquitectónicos singulares, sistemas constructivos, etc., tanto referidas a un único edificio o conjunto como a zonas más extensas, son de una gran ayuda a este propósito y, en gran medida, están sin hacer o por lo menos no se han sistematizado. Un ejemplo a seguir en este campo, por sólo citar uno, puede ser la labor desarrollada en Sevilla por M. A. Tabales en el curso del estudio del antiguo cuartel del Carmen ${ }^{14}$.

A continuación, se presentan dos yacimientos en los que nuestro Servicio ha desarrollado trabajos en los últimos años ${ }^{15}$. Creo que la exposición de los criterios utilizados en su estudio y la síntesis de los resultados obtenidos puede ser la mejor ilustración para una formulación teórica, siquiera tan breve como la que antecede. Intencionadamente, además, se trata de la actuación en escenarios muy distintos. En primer lugar, la iglesia de Pedret es un yacimiento bien conocido en la bibliografía, cuya fal ta de un estudio arqueológico riguroso, había generado una cierta polémica sobre su evolución. En segundo lugar, la casa parroquial de Castellnou de Bages, un edificio muy maltrecho, aparentemente sin apenas val or patri- 
monial, cuyas ruinas, después de haberse demostrado su origen remoto, serán reutilizadas como cementerio.

\section{SANT QUIRZE DE PEDRET}

En 1992 dimos por terminada la excavación en la iglesia de Sant Quirze de Pedret (Cercs), donde habíamos desarrollado trabajos durante tres años. El objetivo de esta investigación, como el de las restantes promovidas por nuestro Servicio, era el de averiguar la evolución de cada uno de los elementos del edificio, desde su fundación hasta el presente, tanto de los que se encontraban a la vista como de los desaparecidos. Este estudio arqueológico constituyó la primera etapa de la restauración del conjunto (19891995), realizada por nuestra institución a petición del Ayuntamiento de Berga, que actual mente tiene el templo a su cargo, y dirigida por el arquitecto jefe, Antoni González (López MulLor, GonzÁlez, 1991; López MuLLOR, CAIXAL, 1995).

\section{Descripción}

El edificio, de dos naves y cabecera tripartita, había tenido de antiguo una gran resonancia en los medios científicos, a causa de la presencia de pinturas murales de mediados del siglo X y de finales del XI (RosselL, 1985). También era importante su arquitectura, pues se trata uno de los ejemplares mejor conservados del prerrománico rural catalán. Todo ello determinó que, en el transcurso de la primera restauración de su fábrica, Ilevada a término por el Servicio entre 1959 y 1964, bajo la dirección del entonces arquitecto director, Camil Pallàs ${ }^{16}$, se desarrollaran trabajos arqueológicos: una corta campaña dirigida por Ricardo Batista, a la sazón arqueólogo del Museo Arqueológico de Barcel ona, ${ }^{17}$ y un vaciado sistemático del interior de la iglesia, bajo las directrices de Modest Buchaca, constructor adjudicatario de las obras ${ }^{18}$.

A nte estos precedentes, cuyos resultados habían permanecido prácticamente inéditos, nuestra intervención se planteó, en principio, como inspección de las zonas del yacimiento que pudiesen permanecer intactas y como estudio de sus fábricas desde el punto de vista arqueológico. Afortunadamente, pudimos comprobar que en el interior

\footnotetext{
${ }^{16}$ Descripción de los trabajos en el CD anexo a LACUESTA, 2000.

${ }_{17}$ Desde 1995, sede central del Museu d'A rqueologia de Catal unya, administrado por el departamento de Cultura de la General itat.

${ }^{18}$ Los diarios de excavación de R. Batista y M. Buchaca, que permanecían inéditos, se reprodujeron, gracias a la amabilidad de sus autores, en: LóPEz MULLOR, 1995. Con todo, una breve síntesis de aquellos trabajos ya había sido publicada en PALLÀs, 1962.

${ }^{19}$ Que en catalán significa el peñasco o el peñascal y, efectivamente, se caracterizaba por la afloración de la roca.
}

del templo todavía se conservaban intactos testigos estratigráficos en puntos interesantes y que su entorno inmediato permanecía casi inexplorado; también se conservaban en buenas condiciones los rellenos de una parte de las cubiertas. En consecuencia, se planteó la investigación extensiva de todos estos lugares: interior, cubiertas y entorno. Además, abrimos al gunos sondeos en una casa vecina del templo, que presenta unos rasgos arquitectónicos reseñables, de clara filiación al tomedieval.

En primer lugar, se procedió a la reexcavación de todo el interior del edificio, vaciándolo por completo. De este modo, se pudieron excavar los testigos que pervivían en el elemento principal de la cabecera, así como en las absidiolas. También quedaban zonas intactas a los pies de la nave central y cerca de uno de los arcos de comunicación con la lateral norte. Paral elamente, se real izó la inspección y registro de los paramentos, poniéndose especial énfasis en la discriminación de todo lo añadido durante la primera restauración, como por ejemplo una cubierta de fal sas vigas de hormigón, que paradójicamente no habían aprovechado los orificios originales, algunos de los cuales se descubrieron. A cto seguido, se excavó en la cubierta de la absidiola norte, la única que proporcionó rellenos de potencia suficiente, aunque los coronamientos de los otros dos elementos de la cabecera tripartita también se inspeccionaron. Lo mismo se hizo con la espadaña de poniente y su acceso, en los que, durante las primeras obras no se había intervenido.

A continuación, se excavó al sur y al oeste del templo, hallándose, respectivamente, la planta completa de la antigua nave sur, con el acceso principal de la iglesia utilizado entre los siglos X y XIII, y una extensa necrópolis que abarcaba desde el siglo IX hasta la edad moderna. Estos trabajos permitieron, además, conocer la abrupta topografía original del lugar de Pedret ${ }^{19}$, que a lo largo de los años fue modificada y suavizada con la aportación de tierras y la construcción de edificaciones.

Los resultados de todas estas tareas sirvieron para confirmar al gunas de las observaciones apuntadas por nuestros predecesores, aportando, además, muchos datos nuevos y, sobre todo, fijando la cronología de las etapas del yacimiento, es decir del edificio, que había provocado tradicionalmente profundas discusiones eruditas (fig. 12). A hora sabemos ciertamente que la iglesia se construyó dentro del último tercio del siglo IX, constando entonces sólo de nave única y cabecera trapezoidal (fig. 6-7); esta última cubierta con bóveda de piedra. El tejado de ambos espacios era "a la romana", formado por una especie de tegulae e imbrices rudimentarios, al gunos ejemplares de los 


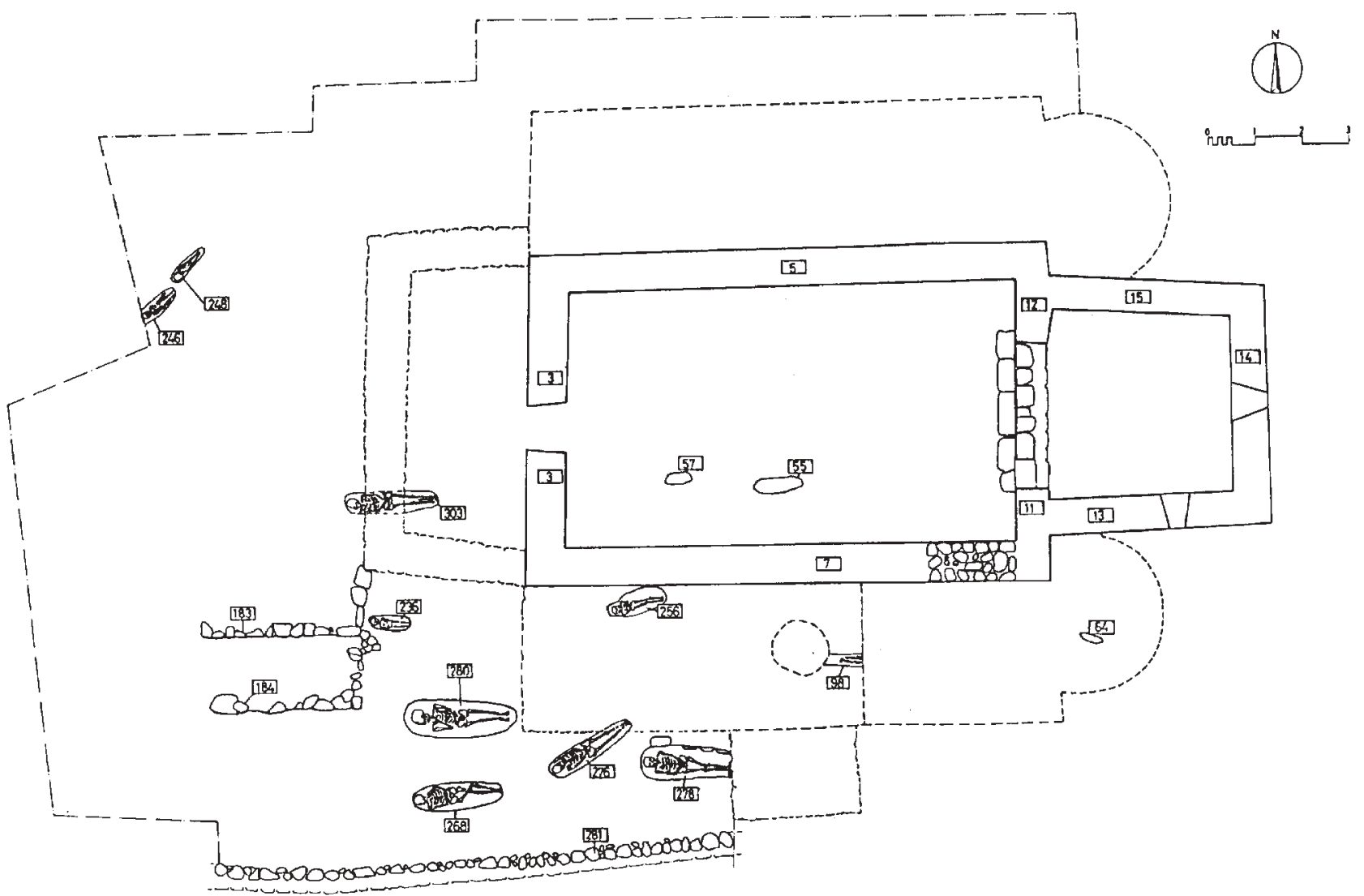

Fig.6. Planta de la iglesia de Pedret a finales del siglo IX, 1994

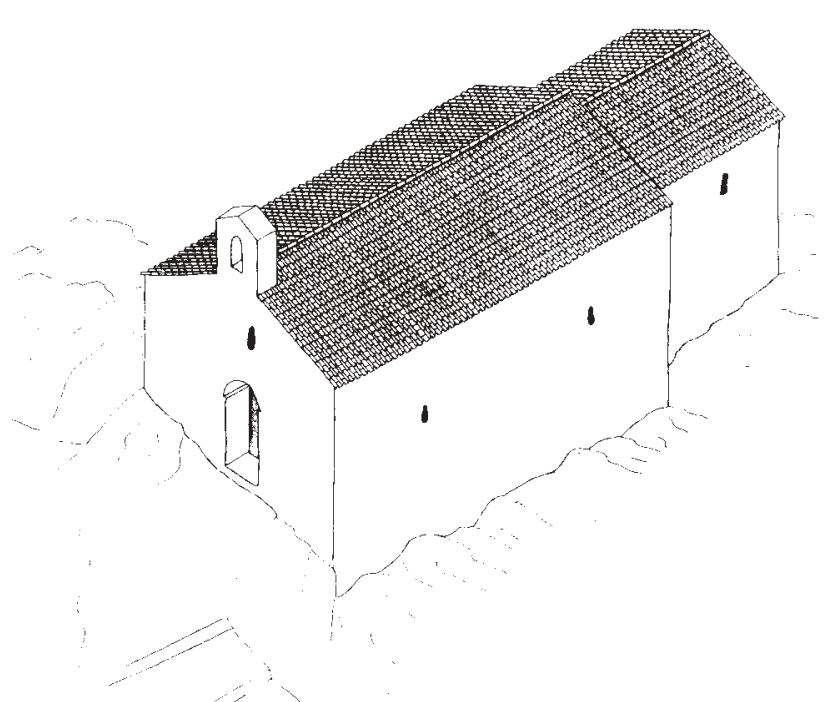

Fig.7. Perspectiva axonométrica de la iglesia de Pedret a finales del siglo IX, 1994

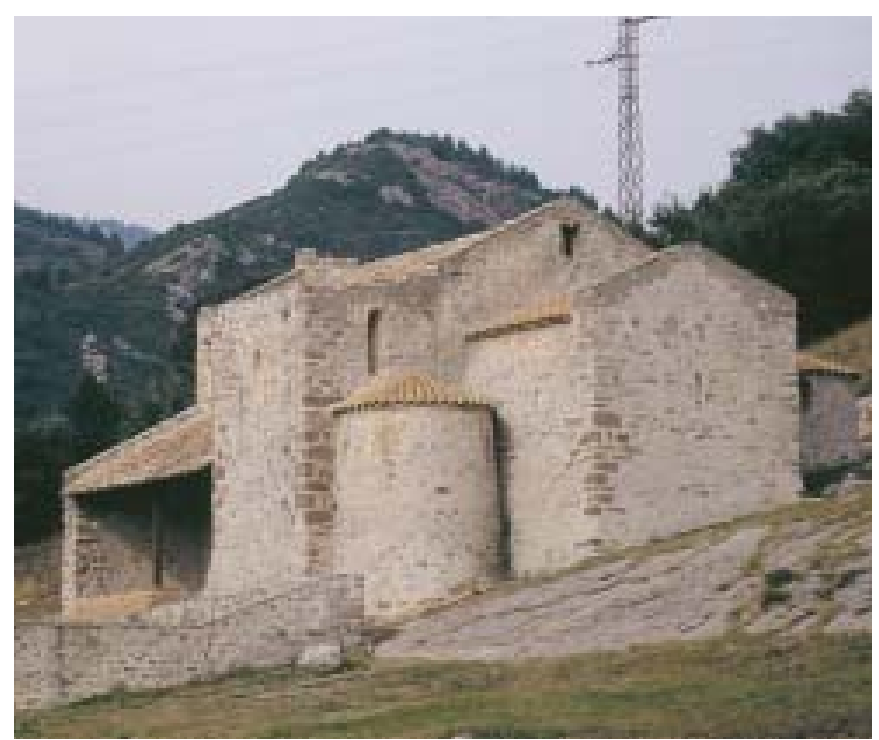

Fig.8. La iglesia de Sant Quirze de Pedret después de las últimas obras de restauración, 1997, foto: Montserrat Baldomà, SPAL 


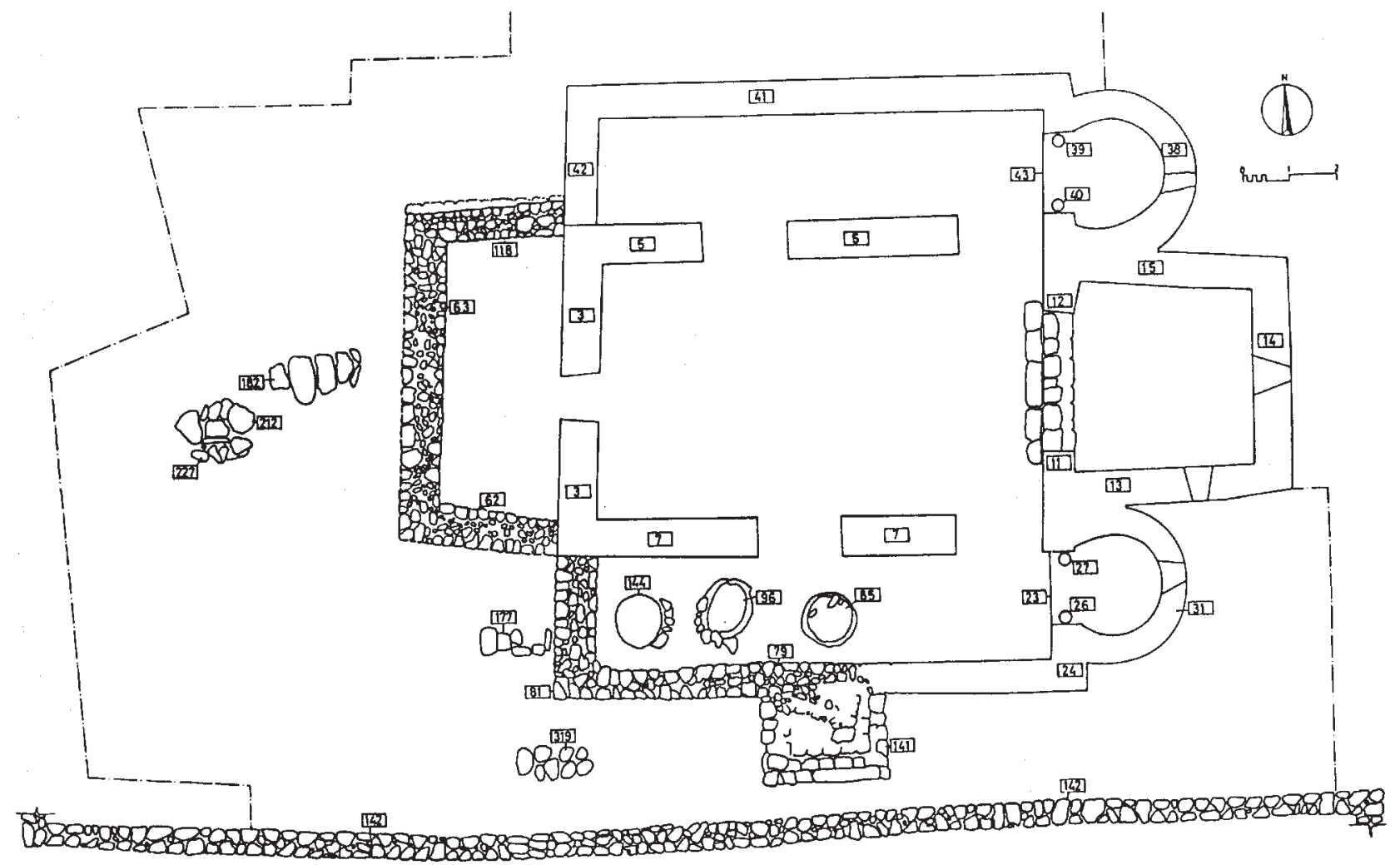

Fig.9. Planta de la iglesia de Pedret a mediados del siglo X, 1994

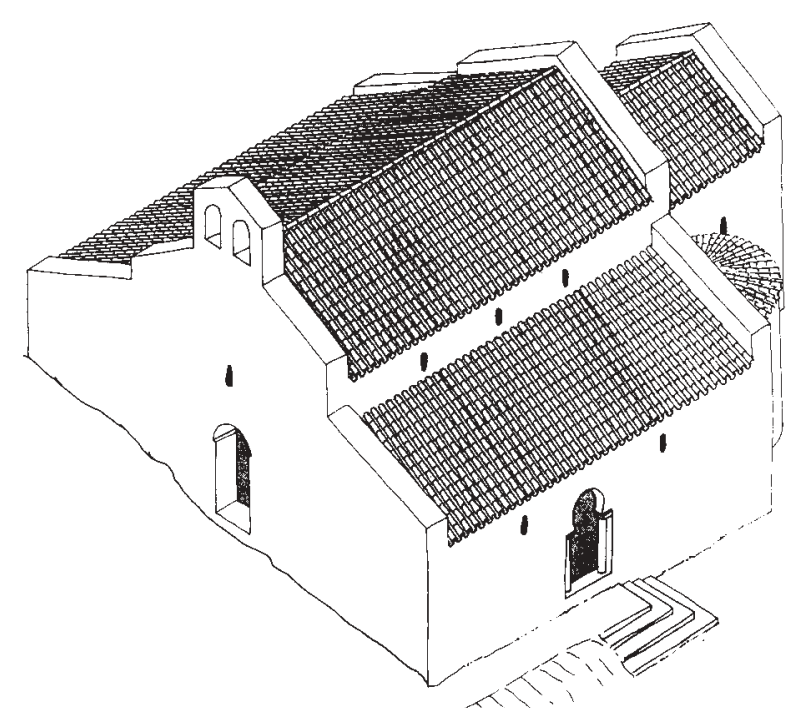

Fig.10. Perspectiva axonométrica de la iglesia de Pedret a mediados del siglo X, 1994

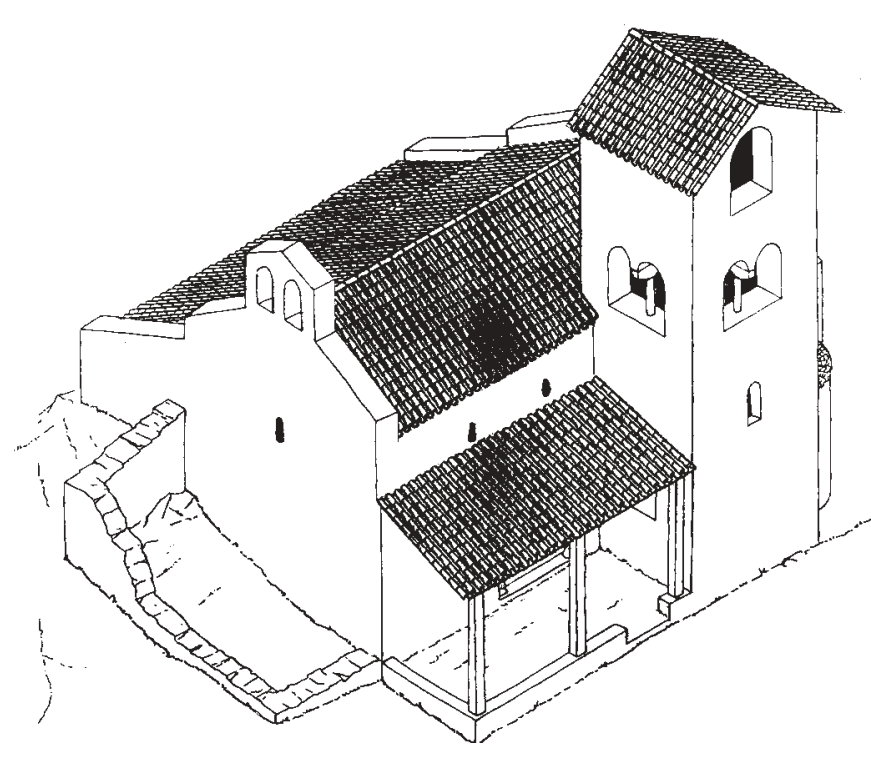

Fig.11.Perspectiva axonométrica de la iglesia de Pedret en el siglo XIII avanzado, 1994 


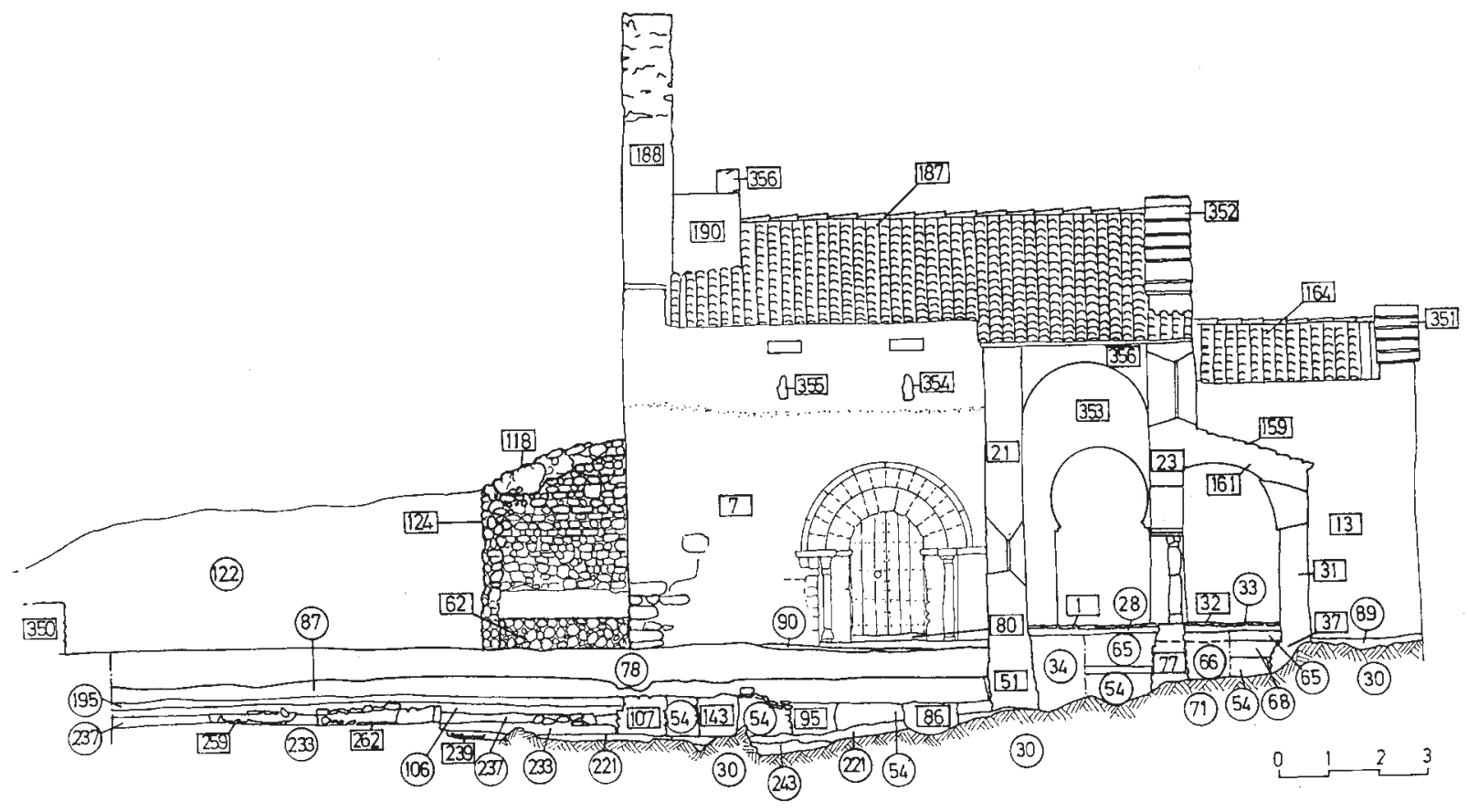

Fig.12. Sección este-oeste de la iglesia de Pedret con indicación de las unidades estratigráficas, 1990

cuales se encontraron formando parte de un depósito cerrado de mediados del siglo X. El pavimento interior era de tierra batida. Alrededor del templo se extendía una sagrera, ocupada por tumbas en fosas muy sencillas, colocadas en la poca tierra que había en un paisaje tan rocoso, 0 en las diacl asas naturales de las formaciones cal cáreas. Al edificio se accedía por una puerta abierta en la fachada de poniente, cuya función fue revel ada por el estudio de paramentos, pues en época posterior se transformó en ventana y, más tarde, desapareció como abertura. Para llegar al acceso se formaron una serie de terrazas artificial es - descubiertas en la excavación- conectadas con el camino tradicional que bordeaba el Llobregat.

\footnotetext{
${ }^{20} \mathrm{H}$ e aquí uno de los antiguos temas de controversia, puesto que ciertos autores (p.e. BARRAL, 1981) interpretaban que la iglesia había sido de tres naves desde su origen y otros (p.e. JUNYENT, 1983) afirmaban que era fruto de dos momentos constructivos. Esta segunda hipótesis fue confirmada por la excavación de los cimientos de la cabecera y el análisis de sus paramentos, que indicaron claramente una diacronía de los el ementos lateral es respecto al central.

${ }^{21}$ La planta de este aula apareció en la excavación, local izándose también la situación de la puerta, cuyos capiteles, muy semejantes a los de las absidiol as también aparecieron en el subsuelo. A partir de todo ello, se pudo reconstruir la imagen del conjunto.

${ }^{22}$ Los del presbierio se conservan actualmente en el Museu Diocesà i Comarcal de Solsona, aunque en el edifico, aprovechando su impronta se ha pintado una reproducción ideal.

${ }^{23}$ D onde se menciona a Sant Quirze de Pedret como dependiente del monasterio benedictino de Sant Llorenç prop Bagà (Guardiola de Berguedà) desde el año 984 (BARAut, 1978: 105).
}

Esta configuración se mantuvo hasta mediados del siglo X, cuando se engrandeció el templo con la colocación de dos naves colaterales encabezadas per sendas absidiolas de planta de herradura (fig. 10-11)20. Los arcos formeros de comunicación con el espacio central -la antigua nave única se construyeron de herradura, similares al que se había utilizado en la fase anterior en la entrada del presbiterio. También adoptaron esta morfología los coronamientos de las embocaduras de las absidiolas y de la puerta principal, que pasaba a situarse a mediodía, en el centro de la nave meridional ${ }^{21}$. En los espacios nuevos se formaron pavimentos de losas $y$, tanto en el presbiterio como en la nave central, se siguieron usando los de tierra batida que poseían. En la sagrera se aportó una gran cantidad de tierras. A poniente eran necesarias para regularizar el entorno del edificio, del que desaparecieron las terrazas de la primera fase, y a mediodía para facilitar el funcionamiento de la nueva puerta. En este punto también se alargó el muro de contención que limitaba el recinto sagrado. Paral elamente a las transformaciones arquitectónicas, en la cabecera principal y en la pared norte de la nave mayor se pintaron los murales más antiguos a que hemos hecho referencia más arriba².

Entre mediados del siglo $\mathrm{X}$ y el primer cuarto del XI, se añadió un cuerpo nuevo al testero occidental del edificio, comunicado con el interior del templo a través de la 
antigua puerta principal del siglo IX, que seguía en uso. Quizá, esta construcción tuvo un cierto carácter monástico, según se podría deducir de su situación topográfica, de la poca documentación escrita de la época que se conoce ${ }^{23} y$ de la posterior evolución del yacimiento. Mientras tanto, en la sagrera se habían depositado numerosas tumbas, fosas sencillas limitadas por losetas vertical es, en algunas de las cual es se marcó la cabecera, al estilo de las antropomorfas, con el mismo material. Debe añadirse que, dentro de la nave sur del templo, se construyeron tres silos alineados, habitual es en otros edificios de este tipo.

El siguiente horizonte cronológico localizado en el yacimiento corresponde a principios del siglo XI. Entonces, el añadido occidental descrito al tratar de la fase anterior fue arrasado y sustituido por un posible porche. También debió edificarse en aquel momento un campanario apoyado sobre el extremo de levante de la nave sur, del que se conservan los arcos en que descansaba su base, así como un capitel de una de sus ventanas geminadas, hallado en la excavación. Paralelamente, se construyó la casa contigua a la iglesia, de planta rectangular y bastante amplia, idónea para una pequeña comunidad monástica, cuyos materiales, estilo y configuración recuerdan a los utilizados en aquella época en Sant Llorenç prop Bagà.

En un momento tardío del siglo XIII tuvieron lugar nuevas modificaciones edilicias (fig. 11). Respondían a la necesidad de reformar el templo, después de que se hubiese derrumbado un buen tramo de la nave sur y seguramente el campanario que la coronaba, así como una gran parte de la cubierta de vigas de madera del resto del templo. Tradicional mente, estos hechos se han asociado a un incendio, no comprobado por procedimientos arqueológicos. Lo cierto es que las obras para paliar las consecuencias de la catástrofe fueron importantes. En la nave central, desde entonces el único espacio que util izarían los fieles, se colocó una bóveda de cañón apuntado apoyada en sendos regruesamientos de las paredes laterales, aligerados por arcos formeros de medio punto, dentro de los cuales, al norte, se situaron capillas que tapaban los arcos de herradura del siglo X. La nave lateral norte también recibió una cubierta de piedra, aunque fue prácticamente incomunicada del resto del templo, puesto que su acceso se limitaba a una puertecita que conectaba con la absidiola norte, también reparada en aquella época y, a través de ésta, con el presbiterio. A mediodía, en vez de rehacerse la antigua aula, sólo se aprovechó su tercio oriental, reconstruyéndose el campanario. El ábside lateral se convirtió en sacristía, comunicada con el presbiterio a través de otra puerta. Por fin, después de un aggiornamento del arco triunfal y del que había comunicado el extremo este de la nave lateral sur - ahora convertido en pequeña capilla que ocupaba las bajos del campanario- con la nave central, otrora de herradura y que pasaron a ser de medio punto, se colocó una portada románica tardía en el lugar donde había estado el segundo de los arcos formeros prerrománicos meridionales.

En el exterior, para ocultar las ruinas de los elementos caídos, se elevó el nivel con nuevas aportaciones de tierras al rededor de todo el edificio. También se erigió un porche rudimentario donde había estado el tramo de nave meridional desaparecido. El elemento de este tipo que había habido a poniente se hallaba asimismo reducido a ruinas, y sólo se aprovechó su pared septentrional, a manera de muro de contención de las aportaciones erosi vas de la vertiente de la montaña donde se erigía el templo.

El conjunto ya no experimentó más cambios significativos hasta el siglo XVIII. Después de la Guerra de Sucesión (1701-1714), además de colocarse un pavimento de losetas cerámicas en todo el interior y renovarse el coro, que funcionaba desde la fase anterior, se transformó la espadaña del testero occidental, que había experimentado diversos cambios morfológicos desde el siglo $X$, y que entonces adquirió unas dimensiones considerables. En este estado se encontraba el templo cuando se inició su primera restauración, en 1959. La segunda le ha devuelto la volumetría de su época de máxima expansión, a mediados del siglo X (fig. 8).

\section{CASA PARROQUIAL DE SANT ANDREU DE CASTELLNOU DE BAGES}

Castellnou de Bages está casi exactamente en el centro geográfico de la provincia de Barcelona, caracterizándose por el poblamiento disperso en masías situadas en un territorio escarpado y boscoso. El casco urbano de la población se compone de unos pocos edificios, entre los que se cuentan el Ayuntamiento y la iglesia de Sant Andreu con su casa parroquial anexa. El templo, de estilo románico lombardo, es bastante conocido por ser un típico ejemplo de planta basilical y conservarse de manera aceptable (J UNYENT et alii, 1984: 200-203). En la actual idad, sól o presenta al gunos añadidos posteriores, como la puerta principal o el campanario, que datan de hacia 1588. En 1976, 1980 y 1983, ya fue objeto de atención por parte de nuestro Servicio, realizándose obras de restauración, tanto en el edificio como en su entorno inmediato (BARAUT, BOVER, 1986: 77-78; LACUESTA, 2000). La casa parroquial, en cambio, se hall laba sumida en una gran postración desde su saqueo e incendio en julio de 1936, a principios de nuestra última guerra civil (fig. 13). 


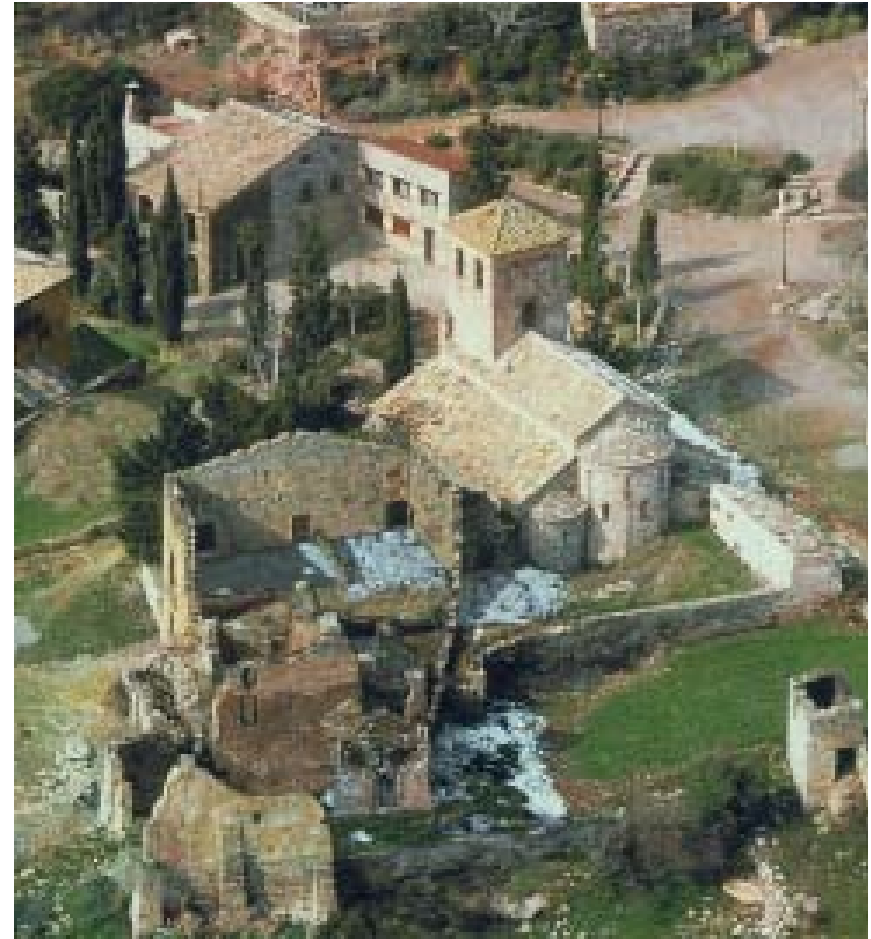

Fig.13. Conjunto de la iglesia de Sant Andreu y las ruinas de la casa parroquial de Castellnou de Bages hacia 1970.SPAL

Este edificio, del que se conocen al gunas fotografías anteriores al incendio, no dejaba de ser una casona más de las que abundan en aquellos parajes. Entonces, era de planta aproximadamente rectangular, dotado de tres alturas y cubierta a dos aguas, y también de una típica balconada apoyada en un porche situado en la fachada principal. En ruinas desde hacía tanto tiempo, se había considerado que carecía de val or arquitectónico, y que debía ser pasto de la piqueta al menor intento de reforma de la trasera de la iglesia. Este paraje se encontraba afeado por un minúsculo cementerio, en el que el añadido de nichos muy recientes perturbaba la visibilidad de la cabecera tripartita de origen románico, uno de cuyos ábsides había sido reconstruido por el Servicio, al estilo medieval, en 1976, después de demoler una sacristía del siglo XVII, cuya construcción lo había hecho desaparecer.

Así las cosas, en 1995, el ayuntamiento de Castellnou de Bages solicitó una vez más la intervención de la

\footnotetext{
${ }^{24} \mathrm{Cf}$. conclusiones en: Garcia TARGa, 1997.

${ }^{25}$ La noticia más antigua conocida data del 981, cf. JUNYENT et alii, 1986; Castellano, 1996; Galí, 2001.

${ }^{26}$ Este arma, quizá olvidada por al guno de los incendiarios 0 acaso propiedad del párroco, es del calibre 6,35 mm, probablemente del modelo "Victoria" 1911, fabricada en Guernica por Esperanza y U nceta. En el M useo Militar de M ontjuïc (Barcelona) se conserva una pieza de este tipo, catalogada con el número 1971165. Para mayores precisiones, cf. CALVó, J IMÉN EZ, 1993.
}

Diputación. En esta oportunidad para poner orden en el espacio que lindaba con la parte posterior del templo, y para remodel ar el campo santo. Los estudios históricos que preceden a todas nuestras intervenciones demostraron, a través de una excavación arqueológica selectiva ${ }^{24}$, que el cementerio, además de las tumbas contemporáneas que al bergaban los nichos, contenía en el subsuelo una interesante necrópolis de las épocas medieval y moderna que se remontaba, como mínimo, al siglo $X$; del mismo modo que las referencias escritas sobre el templo de Sant Andreu ${ }^{25}$. Las trincheras estratigráficas prel iminares pusieron de relieve el buen estado de las tumbas medieval es. No así el de las modernas, apiñadas en poco espacio, a causa del crecimiento demográfico de aquella época. Por tanto, la excavación total de la necrópolis se auguraba larga, trabajosa y muy destructiva en relación a los documentos arqueol ógi cos que contenía. De este modo, la primera propuesta de ampliación del cementerio, que implicaba tales acciones, fue desechada.

Acto seguido, el criterio de la intervención arquitectónica, cuya dirección general asumió también en este caso el arquitecto jefe, Antoni González, dio un vuelco, al considerarse que las ruinas de la casa parroquial (fig. 1415), previamente consolidadas, podían al bergar el nuevo cementerio municipal. Esta al ternativa implicaba conservar in situ casi la totalidad de la necrópol is medieval y, a la vez, poner en valor la cabecera del templo y su entorno meridional.

Una vez decidida la reutilización de la casa, se plantearon los estudios previos a las obras. Por lo que se refiere a la investigación arqueológica, su intención era la de allegar la mayor cantidad de información con el mínimo dispendio posible, intentando mantener el yacimiento prácticamente intacto. En consecuencia, después de las trincheras preliminares en la necrópolis, que tan útiles se revelaron para la orientación posterior de la actuación, se procedió al estudio estratigráfico de la casa rectoral. En primer lugar, se excavó el estrato de destrucción depositado en julio de 1936 que, en ciertas zonas, alcanzaba una potencia de más de dos metros. Esta capa, formada sobre pavimentos y forjados, incluía la cubierta de tejas, restos de techumbre de los pisos intermedios y los el ementos que habían formado las paredes. En este caso una ingente cantidad de arcilla, procedente del tapial de la primera planta, así como mampostería del segundo piso y de algún pequeño tramo de la planta baja, que en general había permanecido en pie. El material hallado en esta excavación fue abundante y heterogéneo. J unto a los auténticos "fósiles directores", como restos de ornamentos sacerdotales 


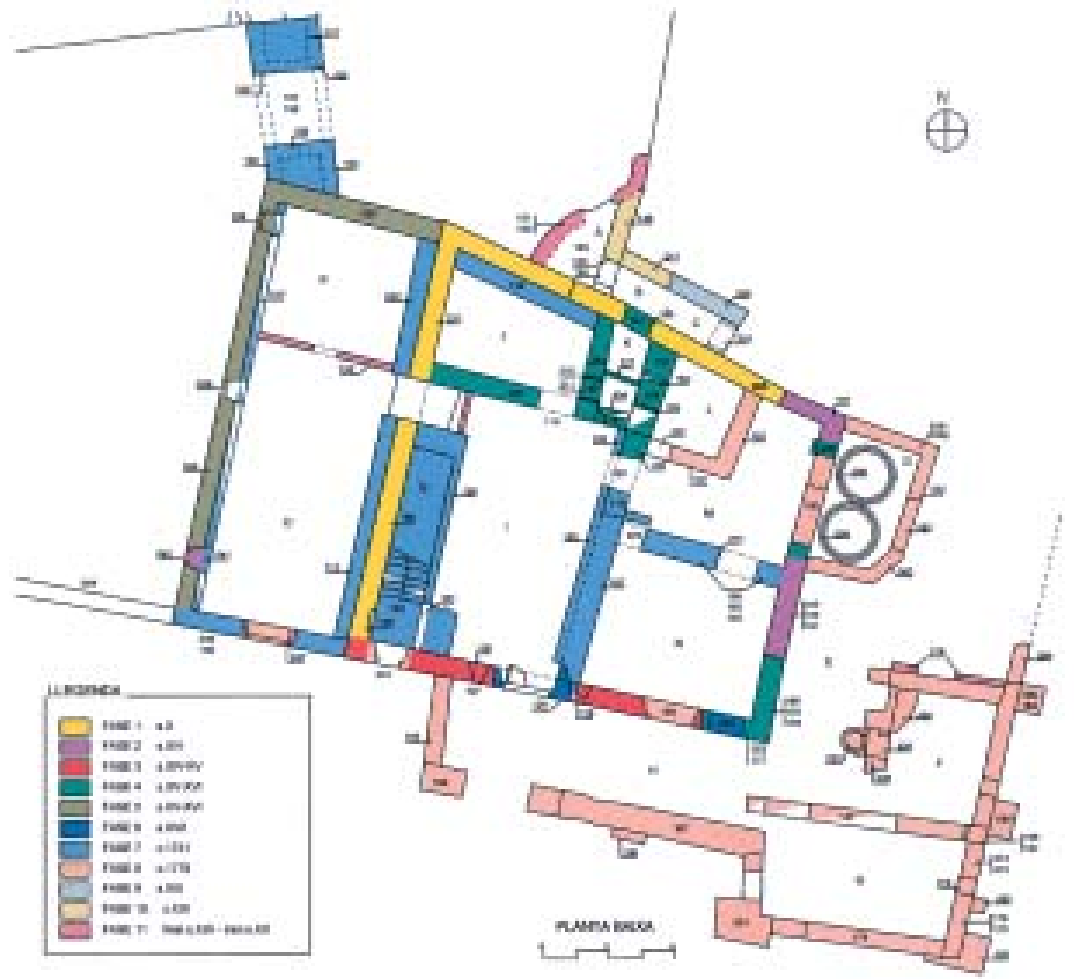

Fig.14. Planta de la casa parroquial de Castellnou de Bages con indicación de la cronología de las diferentes estructuras, 1998

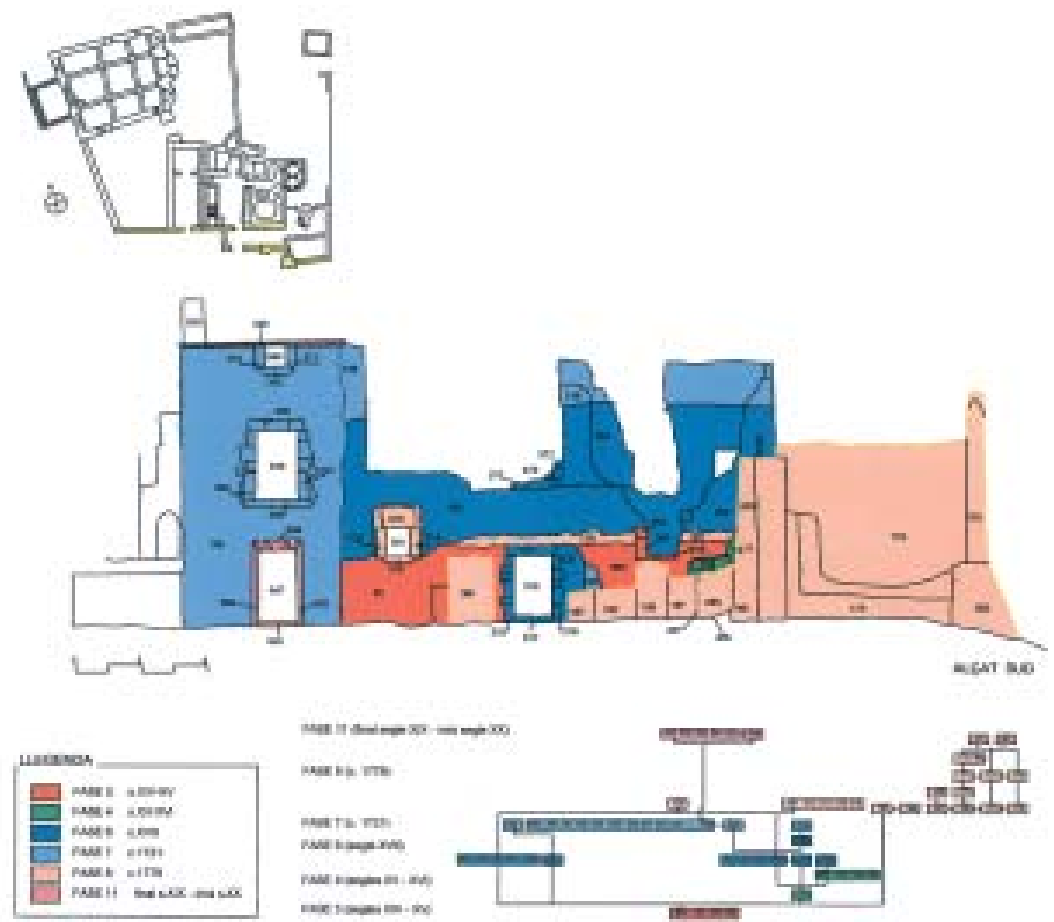

Fig.15. Alzado de la fachada meridional de Castellnou de Bages con indicación de las unidades estratigráficas y los horizontes cronológicos, 1998 
chamuscados 0 una pistola de pequeño cal ibre fabricada en el segundo o tercer decenio del siglo XX ${ }^{26}$, apareció una gran cantidad de cerámica de la edad moderna, indicándonos que una de las grandes reformas que sufrió el edificio, en el curso de la cual se le dotó del primer piso de tapial, tuvo lugar en el siglo XVII.

A cto seguido, se abrieron pequeños sondeos, tanto en la planta baja como en los senos de las bóvedas del primer piso. Sin embargo, el grueso del estudio arqueológico correspondió al análisis estratigráfico de paramentos (fig. 14-15) ${ }^{27}$. Ya se ha apuntado que en nuestro caso es un método de trabajo utilizado cotidiana e indiscriminadamente, teniendo en cuenta los yacimientos a los que nos enfrentamos y la utilidad y economía del procedimiento. $Y$ sus resultados en Castel Inou fueron de lo más alentador. EI fichaje generalizado de las unidades estratigráficas y el anál isis de las interrelaciones entre paramentos y otros elementos constructivos, así como la identificación tipológica de las diferentes fábricas, nos llevaron a distinguir once fases edilicias dentro de tan aparentemente modesto y anodino edificio, las cual es pudimos datar gracias a la tipología, a dos fechas inscritas en sendas ventanas y también a la extrapolación, a través de la secuencia estratigráfica general, de las dataciones absolutas obtenidas a raíz de los pequeños sondeos real izados.

\section{Conclusiones $^{28}$}

El análisis arqueológico de los paramentos de la casa rectoral de Castellnou de Bages, contrastado con los datos proporcionadas por las fuentes escritas y oral es y también por al gún pequeño sondeo, ha dado unos resultados que, al empezar el trabajo, parecían lejos de poderse obtener. La primera fase edilicia del yacimiento, localizada en la base de las paredes septentrional y occidental del cuerpo original del edificio, es posible remontarla al siglo X. Pudo

\footnotetext{
${ }^{27}$ En este trabajo colaboraron Anna Gutiérrez y A riadna Traveset, arqueólogas. Los planos de base, imprescindibles para el análisis arqueológico, fueron elaborados por los arquitectos colaboradores R afael Vila y Eugènia Vidal y los delineantes del Servicio J ordi Serra y M aite Gómez.

${ }^{28}$ Sobre la investigación en este yacimiento, pueden verse más detalles en: LóPEZ MulLor, CAIXAL, PAN CORBo, en prensa y LóPEZ M ULLOR, GUtiérRez, en prensa. ${ }^{29}$ BOLÒS, PAGĖs, 1982: 80. La datación general propuesta por estos autores se ha confirmado a grandes rasgos, y también se ha matizado, a lo largo de las nume rosas excavaciones real izadas en los últimos años. En los diferentes volúmenes de la obra general Catal unya R omànica (Barcel ona, 1984-1998) se puede observar un auténtico corpus de enterramientos de esta clase.

${ }^{30} \mathrm{H}$ oy desaparecida, y cuyos restos pudieran hallarse bajo el templo actual que, como se ha dicho, es románico lombardo, del siglo XI.

${ }_{31}$ Català, 1976: 632-635. El topónimo Castellnou, literalmente Castillo N uevo, aparece por primera vez el año 1001, habiéndose asociado con una torre que existe en el mismo término municipal.

${ }^{32}$ Cerámica catal ana decorada en verde y manganeso.
}

corresponder a una construcción de medianas dimensiones y planta rectangular, lo que en la Cataluña medieval se conocía como una sala, y es posible caracterizarla cronológicamente por la presencia del aparejo denominado opus spicatum, atestiguado largamente en edificios al tomedievales catal anes, y cuyo apogeo cabe situar en la centuria indicada. Tal datación concuerda con las informaciones proporcionadas por la excavación de la necrópolis, donde se encontró una tumba antropomorfa recortada en el terreno natural. Esta clase de enterramientos, bien conocidos en Cataluña y Castilla, aunque en esta última área puedan ser algo más tardíos, poseen en nuestro territorio un arco cronológico bien delimitado, que comprende desde mediados del siglo X a los primeros años del siglo X ${ }^{29}$. En esta oportunidad la documentación escrita sobre el templo también se remonta al siglo X (981), haciéndose la primera referencia al castillo de Castellnou en 1020, con motivo de una transferencia feudal de su propiedad.

Todo ello incita a pensar que en un momento avanzado del siglo X, quizá al mismo tiempo que la iglesia originaria ${ }^{30}$, se erigió el edificio que nos ocupa. Éste, atendiendo a la nula documentación sobre casas parroquiales en aquella época - la de Castellnou no aparece en las fuentes escritas hasta 1425-, quizá pudiera relacionarse con el primitivo castillo, tal y como se había planteado hace años, sin conocerse todavía la presencia de los paramentos de opus spicatum ${ }^{31}$. En todo caso, teniendo en cuenta su porte, se le puede atribuir sin ambages una cierta categoría, propia, por ejemplo, de una casa fuerte.

La segunda fase, en que la planta del cuerpo central del edificio debió adoptar su configuración actual, se muestra menos explícita, puesto que sus estructuras se caracterizan por un aparejo de mampostería poco el ocuente, de piedra del lugar colocada en hiladas rudimentarias. $\mathrm{N}$ o posee, sin embargo, fragmentos cerámi cos interpol ados en la fábrica a modo de cuñas ni tampoco piedrecitas de idéntica función, que aparecen en los edificios rurales a partir de finales de la edad media. Además, tal y como ocurre con el opus spicatum, su el emento de cohesión es la argamasa de cal. Todo ello puede llevarnos a concluir que nos hallamos ante una obra bajomedieval, circunstancia que confirma el hal lazgo de cerámica del siglo X IV ${ }^{32}$ en los pavimentos de tierra batida contemporáneos de estas paredes.

D urante la tercera fase se erigió la fachada meridional que conocemos (fig. 15), que más tarde fue dotada de dos puertas, una relativamente centrada, seguramente la principal y otra al sudeste, ambas de construcción sencillísima con montantes de piedra cal cárea apenas desbastada y din- 


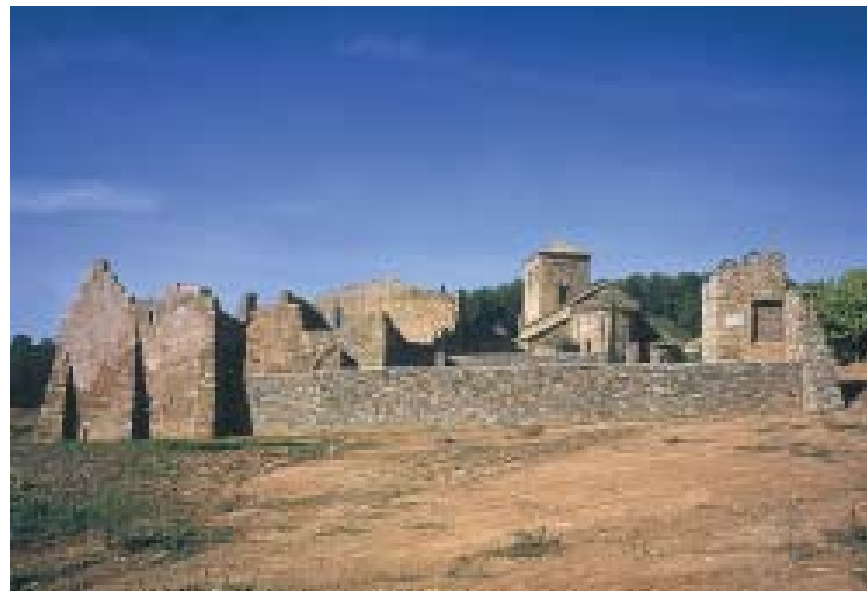

Fig.16. La casa parroquial de Castellnou de Bages después de su restauración, 2000, foto: Montserrat Baldomà, SPAL

teles de madera. Si a ello unimos el aparejo de la fachada, de piedra escasamente labrada colocada en hiladas y, esta vez sí, con fragmentos de tejas o piedrecitas a modo de cuña, habríamos de situarnos hacia el siglo XV.

A lgo más tarde - cuarta fase-, la puerta bajomedieval del nordeste, probablemente del siglo XIV, fue sustituida por un arco apuntado construido a partir de bloques de arenisca bien tallada, que comunicaba con un cuerpo anexo hoy desaparecido. Ignoramos cuándo pudo añadirse este el emento. N o obstante, su apariencia nos hace llevarlo a un momento avanzado en el uso del estilo gótico, hacia finales del siglo XV o principios del XVI, debiéndose erigir también entonces los muros que limitaban una buena parte de los ámbitos de la planta baja de la casa33.

A lo largo de los primeros decenios del siglo XVII tuvo lugar la quinta fase constructiva, durante la que el primer piso del cuerpo principal adquirió su aspecto actual, a tenor de la fecha proporcionada por la cerámica procedente de sus paredes de tapial caídas. Por su parte, el cuerpo de poniente, en el que se distinguen claramente dos fábricas, fue erigido hacia 1600, momento al que corresponde el aparejo del tramo inferior de la fachada

${ }^{33}$ Poseemos un terminus post quem para el arco: la fecha del siglo XIV de la puerta a la que sustituyó. A demás, dentro de al gunas de las paredes de las estancias que se construyeron en esta misma fase, se han encontrado fragmentos de cerámica de Barcel ona decorada en azul, cuyo floruit se sitúa en el siglo XVI.

${ }^{34}$ Que fueron estudiadas, como el resto del material numismático hallado en la excavación, por M aría Clua M ercadal, conservadora del Gabinet N umismàtic de Catalunya del MNAC

${ }^{35}$ La dedicación vitivinícola del clero, de la que conocemos paralelos en Santa M aria de Foix (Torrellas de Foix) o Pierola, por mencionar sólo dos ejemplos de instalaciones bien conservadas en casas parroquiales, se explica dentro de una gran eclosión de tal género de actividad en Cataluña hasta bien entrado el siglo XIX -la filoxera llegó a España en 1878-, que supuso la plantación de viñas en una gran parte de la superficie cultivable del país, roturada en al gunos casos por primera vez, desplazando bosques o pastos.

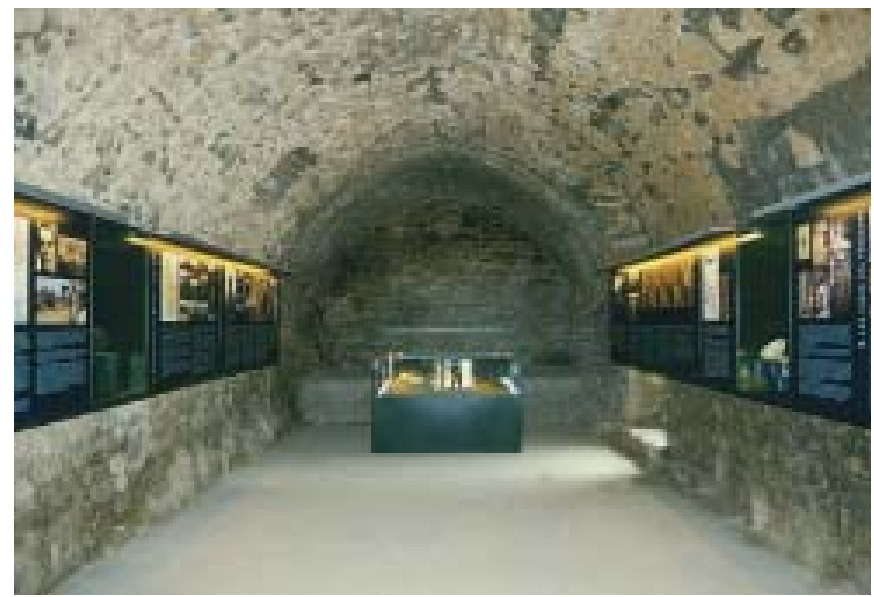

Fig.17. Centro de interpretación histórica situado en la casa parroquial de Castellnou de Bages, 2000, foto: Montserrat Baldomà, SPAL

occidental, cuya al tura coincide con la de la planta baja del cuerpo central (fig. 15). Las plantas más altas de aquel momento fueron sustituidas hacia 1721 por las que se han conservado hasta hoy. La fecha de esta importante modificación, que también supuso el añadido de un nuevo piso y diversas reformas interiores en el cuerpo central, aparece en un balcón situado a suroeste de la casa, en el que también figura el nombre del patrocinador de la obra, el reverendo Félix Puig. A demás, se ha comprobado gracias a la excavación en los senos de las bóvedas que se col ocaron en los dos cuerpos principales del edificio, que ha proporcionado cerámica azul catalana de la primera mitad del siglo XVIII, decorada con la orla de la botifarra. También aparecieron sendas monedas bajo el pavimento de losas de la planta baja y en la fábrica de un pesebre, acuñadas ambas por el archiduque Carlos, entre 1707 y $1711^{34}$. Se trata, por tanto, de una verdadera reforma general del edificio, muy característica de la pujanza económica general que siguió al final de la Guerra de Sucesión, y que se comprueba en multitud de construcciones rurales, tanto religiosas como civiles.

No mucho después, hacia 1779 , se tiene constancia de la abertura de una ventana en la fachada principal de la casa, a poniente de la puerta de entrada. N o obstante, la mayor modificación realizada a partir de aquel momento consiste en el añadido del porche y la bal conada a la fachada sur - que quizá sustituían una estructura semejante anterior-, coincidiendo con la erección de las dos crujías situadas al sudeste. Sabemos, a través de testimonios orales y escritos, que en este cuerpo periférico estuvo instalado el Ayuntamiento del pueblo hasta la Guerra Civil de 1936-1939. Tal construcción, de gran homogeneidad, con un primer piso de piedra a modo de zócal o y los dos restan- 
tes de tapial, se erigió probablemente al mismo tiempo que un cuerpo con dos lagares cilíndricos situado al nordeste (fig. 14) ${ }^{35}$, cuyo añadido cegó el arco gótico construido años antes y dio lugar al arrasamiento de la hipoté tica estructura a la que hasta entonces habría conducido el arco citado.

Las siguientes reformas, hasta llegar a las once fases citadas más arriba, se han de situar en época reciente y son de menor entidad, por lo tanto obviaremos su descripción, aunque, gracias al análisis de las fábricas, se hayan podido seguir pormenorizadamente.

$\mathrm{H}$ oy en día, una vez terminadas las obras de restauración de la antigua casa parroquial, ésta acoge el cementerio del pueblo (fig. 16) y un pequeño centro de interpretación histórica, en el que se dan a conocer al visitante los resultados de las investigaciones real izadas (fig. 17).

\section{Bibliografía}

Azkárate A., Fernández De Jáuregui A., N úñez M ., 1995, D ocumentación y análisis arquitectónico en el País Vasco. Algunas experiencias Ilevadas a cabo en Alava, España, en $L$ er el documento construido = Informes de la Construcción (Madrid), 46, n. 435, enero-febrero, pp. 65-78.

BARAUT A. M., 1978, Les actes de consagració d'esglésies del bisbat d'U rgell, U rgellia (L a seu d'U rgell), 1, pp. 11-82.

BARAUT A. M., BOVER I., 1986, Església parroquial de Sant Andreu de Castellnou, M emòria 1984, Servei deCatal ogació i Conservació de M onuments de la Diputació de Barcel ona. Barcelona, pp. 77-78.

BARRAL X., 1981, L'art pre romànic a Catalunya. Segles IX -X, Barcelona

BolÒS J., PAGÈS. M., 1982, Les sepultures excavades a la roca, en M. RIU (dir.), N ecròpol is i sepultures medievals de C atalunya, anexo 1 de A cta M ediaevalia. Barcelona, pp. 59-103.

BrogIOLO G. P., 1988a, A rcheologia del 'edilizia storica, Como.

BRoGiolo G. P., 1988b, Campionatura e obiettivi nell'analisi stratigrafica degli el evati, en R. Francovich, R. PARenti (a cura di), A rcheol ogia e restauro dé monumenti, I ciclo di lezioni sulla ricerca applicata in A rcheologia, Certosa di Pontignano (Siena), 28 settembre-10 ottobre 1987, Firenze, pp. 335-346.

BROGIOLO G. P., 1995, Arqueología estratigráfica y restauración, en L er el documento construido $=$ Informes de la Construcción (Madrid), 46, n. 435, enerofebrero, pp. 31-36.

CABAller O L., 1980, La iglesia y el monasterio visigodo de Santa María de Melque (Toledo). A rqueología y Arquitectura, Excavaciones A rqueológicas en España, 109, Madrid.

CABALLERO L., 1987, El método arqueológico para la comprensión del edificio. Dual idad sustrato arqueol ógico-estructura, C ur so de mecánica y tecnol ogía de los edificios antiguos, Colegio Oficial de Arquitectos de Madrid. Madrid, pp. 13-59.

CABALLER O L., 1995, Método para el análisis estratigráfico de construcciones históricas o 'lectura de paramentos', en $L$ er e documento construido = Informes de la Construcción (Madrid), 46, n. 435, enero-febrero, pp. 37-46.

Caballero L., Cámara L., Latorre P., Matesanz P. 1991-1992, La iglesia prerrománica de S. Pedro el Viejo de Arlanza (H ortigüela, Burgos), N umantia. A rqueol ogía en Castilla y L eón (Sal amanca), 5, pp. 139-165.

Caballero L., CámARA, L., 1995, Un caso de lectura de paramentos y argumentación científica. S. Pedro el Viejo de Arlanza, Burgos, España, en Ler el documento construido = Informes de la Construcción (Madrid), 46, n. 435, enero-febrero, pp. 79-90.

Caixal A., Fierro J ., López M ullor A., 1991, Resultats de l'excavació arqueològica en la galeria alta del Pati Manning de I'antiga Casa de Caritat, en A. Gonzáles, A. López Mullor (dirs.), Simposi A ctuacions en ed patrimoni edificat medieval i modern (segles X al X VIII). I. La intervenció arquitectònica, II. La recerca arqueològica. B arcel ona, 5-7 d'octubre de 1989, Quaderns
Científicis i Tècnics, Servei del Patrimoni Arquitectònic Local, Diputació de Barcelona, 3. Barcelona, pp. 16-20.

CaiXAL A., SolÉ X., 1991, Resultats de l'excavació a la capella de Sant Bartomeu de N avarcles, en González, A., López MulLoR, A. (dirs.), Simposi A ctuacions en el patrimoni edificat medieval i modern (segles $X$ al XVIII). I. La intervenció arquitectònica, II. La recerca arqueològica. B arcelona, 5-7 d'octubre de 1989, Quaderns Científicis i T ècnics, Servei del Patrimoni Arquitectònic Local, Diputació de Barcelona, 3. Barcelona, pp. 59-66.

CALVÓ J. L., J IMÉnEZ E., 1993, 1840-1940. Cien años de pistol as y revól veres españoles, Pontevedra.

Carandin I A., 1977, Dieci anni dopo, Ostia IV, Studi Miscellanei, 23. Roma, pp. 419-424.

CARAN DINI A., 1981, Storie della Terra. M anuale del lo scavo archeol ogico, Bari.

CAstAnyer P., TREm OLEDA J., 1999, La Villa romana de Vilauba: un exemple de l'ocupació o explotació romana de territori a la comarca del Pla de l'Estany, Ajuntament de Banyoles, M useu d'A rqueologia de Catalunya. Girona.

CAstellan o A., 1996, Dades historiogràfiques. Església Parroquial de Sant A ndreu de Castellnou (Bages). Informació i prediagnòstic. Servei de Patrimoni A rquitectònic Local. Diputació de Barcel ona (inédito).

CatalÀ P., 1976, Castellnou de Bages, Els castells catalans, V, Barcelona, pp. 632-635.

FierRo J., (en prensa), L'excavació a l'església de Sant Pere de Serrallonga (Alpens), en II Congrés d'A rqueologia medieval i moderna de Catalunya. Sant Cugat del Vallès, abril de 2002, Associació Catal ana de Recerca en A rqueologia Medieval.

FIERRO J., 1991, Resultados de las excavaciones realizadas en la iglesia de Santa Eulàia de Riuprimer, en González A., López Mullor A. (dirs.), Simposi A ctuacions en el patrimoni edificat medieval i modern (segles X al X VIII). I. La intervenció arquitectònica, II. La recerca arqueol ògica. B arcel ona, 5-7 d'octubre de 1989, Quaderns Científicis i T ècnics, Servei del Patrimoni Arquitectònic Local, Diputació de Barcelona, 3. Barcelona, pp. 52-56.

GaLí D., 2000, Estudi documental sobre el nudi antic de Castelnou de Bages, Diputació de Barcelona, Servei Patrimoni Arquitectònic Local (inédito).

GARCÍA TARGA J ., 1997, M emòria dels treballs arqueol ògi cs duts a termeal cementiri de l'esgl ésia de Castellnou de B ages (B ages, B arcelona), juliol-agost de 1997, Servei del Patrimoni Arquitectònic Local de la Diputació de Barcelona (iné dita).

H ARRIS H .C., 1975, The Stratigraphic Sequence: a Question of Time, W orld A rchaeol ogy, VII-1, pp. 109-121.

HARRIS H.C., 1977, Units of Archaeological Stratification, Norwegian A rchaeological Review, X, 1-2, pp. 84-106.

HARRIS H.C., 1979a, The Laws of Archeological Stratigraphy, World A rchaeology, XI-1, pp. 111-117.

H ARRIS H .C., 1979b, Principles of A rchaeol ogical Stratigraphy, London.

JUNYENT E., 1983, L'arquitectura religiosa a Catalunya abans de romànic, Barcelona.

JUNYENT E. et alii, 1984, Castellnou de Bages. Sant Andreu de Castellnou, Catalunya Romànica, Fundació Enciclopedia Catalana. Barcelona. XI. El B ages. Barcelona, pp. 200-203.

LACUESTA R., 2000, Restauració monumental a Catalunya (segles XIX i XX). $L$ 'aportació de la D iputació de Barcelona, Mongrafies, 5, Àrea de Cooperació, Servei del Patrimoni Arquitectònic Local, Barcellona.

LATORRE P., 1995, Análisis arqueológico de los paramentos del faro romano Ilamado Torre de H ércules. La Coruña, España, en L er el documento construido $=$ Informes de la Construcción (Madrid), 46, n. 435, enero-febrero, pp. 47-50.

LATORRE P., CABALLERO L., 1995, La importancia del análisis estratigráfico de las construcciones históricas en el debate sobre la restauración monumental, en $L$ eer el documento construido $=$ Informes dela Construcción (Madrid), 46, n. 435, enero-febrero, pp. 5-18.

LóPeZ Mullor A., 1982, Ermita de la Mare de Déu de Bellvitge, L'H ospitalet de Llobregat, Les excavacions arqueol ògiques a Catalunya en es darrers anys, Excavacions A rqueològiques a Catalunya, 1, Servé d'A rqueologia, $G$ eneralitat de $C$ atalunya, Barcel ona, pp. 380-382.

LÓPEZ M ULLOR A., 1984a, Església de Sant Vicenç de Malla (II Fase). Les fonts arqueològiques. Descripció de l'edifici, M emòria 1983, Servé de Catalogació $\mathrm{i}$ Conservació de M onuments de la D iputació de B arcelona. Barcelona, pp. 95-104, 246-249. 
López Mullor A., 1984b, Sant Vicenç de Malla, Catalunya Romànica II. Osona I. Barcelona, pp. 296-306.

LÓPEZ MULLOR A., 1986, Consideracions metodològiques sobre l'actuació del Servei de Catalogació i Conservació de M onuments en el camp de la recerca arqueol ògica, M emòria 1984, Servei de Catalogació i Conservació de M onuments dela D iputació de B arcelona. B arcelona, pp. 19-21, 158-160.

LÓPEZ MULLOR A., 1988, Excavacions a l'ermita de la Mare de Déu de Bellvitge. L'H ospitalet de Llobregat, Barcelonès. Campanyes 1979-1981, I dentitats (l'H ospital et de Llobregat), 1, pp. 17-35.

LóPEZ MULLOR A., 1989, Las cerámicas romanas de paredes finas en Cataluña, Quaderns Científicis i Tècnics, Servei del Patrimoni Arquitectònic Local, Diputació de Barcelona. Barcel ona, 2. Barcelona.

LÓPEZ M ULLOR A., 1990a, Set anys d'invesgatició arqueològica del patrimoni arquitectònic, M emòria 1985-1989, pp. 13-18.

LÓPEZ MULLOR A., 1990b, Església parroquial de Santa Eulàlia de Riuprimer. Treballs d'arqueologia, M èmoria 1985-1989, pp. 153, 158.

LópeZ MULLOR A., 1992, L'H ospitalet de Llobregat. Santa Maria de Bellvitge. Arquitectura. Jaciment arqueològic, $C$ atalunya Romànica $X X$. El $B$ arcelonès, El Baix Llobregat, El M aresme. Fundació Enciclopèdia Catalana. Barcelona, pp. 266-267.

LÓPEZ M ULLOR A. , (ed.), 1995, Investigacions arqueològiques i històriques al Berguedà (II). Sant Llorenç prop Bagà. Sant Quirze de Pedret, Quaderns Científicis i Tècnics, Servei del Patrimoni Arquitectònic Local, Diputació de Barcelona. Barcelona, 6

LóPEZ MULLOR A., 1998, Céramique tardo-républicaine et augustéene trouvée à Emporia, A ctes du Congrès d'I Itres, Société Française d'Étude de la Céramique Antique en Gaule. Marsella, pp. 131-138.

LÓPEZ MULLOR A., 2000, El castel i les torres. G uia del patrimoni arquitectònic de Castelldefels I, Ajuntament de.Castelldefels. Castelldefels.

LóPez M ulLOR A., CAIXAL À., 1995, Església de Sant Quirze de Pedret. Cercs, Q uaderns $C$ ientífics i Tècnics, 6 . Investi gacions arqueol ògiques i hi stòriques al $B$ erguedà (II). M onestir de Sant Llorenç prop Bagà. E sglésia de Sant Quirze de Pedret. Servei del Patrimoni Arquitectònic Local. Diputació de Barcel ona, pp. 179-255.

López Mullor A., Caixal A., Fierro J., Domingo E., Juan M., 1986, Excavaciones en la iglesia de Santa Càndia d'Orpí (Barcelona), A ctas de I C ongreso de A rqueología M edieval Española, H uesca 1985, Zaragoza, pp. 95-110.

López Mullor A., Caixal A., Fierro J., 1989, Resum cronològic. Resultats de l'excavació arqueològica, en A. Gon Zález (dir.), E sgl éía de Santa Càndia d'Orpí, Diputació de Barcelona, Servei del Patrimoni Arquitectònic, Monografies, 1, Barcelona, pp. 7-9, 35-42.

López Mullor A., CaiXAl A., Fierro J ., 1997, Un nou jaciment al'a. ger de Tarraco: la villa romana del castell de Cubelles, Hispània i Roma. $D$ 'A ugust a Carlemany. Congrés d'homenatge al Dr. Pere de Palo/2 (A nnals de I'Institut d'E studis G ironins, X XX VII, 1996-1997), Girona, pp. 853-873.

López Mullor A., CaiXal A., Fierro J., 1998, El lloc del castell de Cubelles a l'època antiga i medieval (s. II aC-s. XV) a través de l'arqueologia, Quaderns Científicis i Tècnics, Servei del Patrimoni Arquitectònic Local, Diputació de Barcelona, 10, pp. 136-178.

López Mullor A., Domingo R., Caixal À., Fierro J., 1986, Excavaciones en la iglesia de Sant Vicenc de Malla (Barcelona), A ctas de I Congreso de A rqueol ogía M edieval Español a, H uesca 1985, Zaragoza, pp. 79-94.

LÓPEZ M ULLOR A., EsTANY I., 1993, L'excavació a l'àrea de les termes romanes de Sant Boi de Llobregat (campanyes de 1989-1991), I. III Simposi sobre restauració monumental. Barcelona, de 19 al 21 de novembre de 1992, II. Estudis, informes i textos del Serve de Patrimoni A rquitectònic Local, Quaderns Científicis i T ècnics, Servei del Patrimoni Arquitectònic Local, Diputació de Barcelona, 5, pp. 339-362.

López Mullor A., Estany I., N iño V., Vila J.M., FÀbregas M., Parera M., Clua M., Götzen V., 1998, Torre del Baró, Viladecans. Arqueologia, Monografies, 4, Diputació de Barcelona, Àrea de Cooperació, Servei del Patrimoni Arquitectònic Local. Barcelona.

López Mullor A., Fierro J., CAiXAl A, 1993, L'excavació a l'església de Sant J aume Sesoliveres (I gual ada, A noia), G ala (Sant Feliu de Codines), 2, pp. 259-276.

López Mullor A., Fierro J., Caixal À, 1995, La excavación en la iglesia de Sant Jaume Sesoliveres (Igualada, Barcelona), 10 Congresso de A rqueol ogia Peninsular. Porto 1993, vol. V (Trabal hos de A ntropol ogia e E tnol ogia, XXXV, fasc. 1), Oporto, pp. 431-450.
López Mullor A., Fierro J., Caixal À., Castellano A., 1992, La primera Vilanova. L'establiment ibèrici la vil.la romana d'A rró, D arró 0 A darró de Vilanova i la $\mathrm{G}$ eltrú. Síntesi dels resultats de les darreres recerques arqueol ògiques i histơriques, Sant Sadurní d'Anoia.

López Mullor A., Fierro J., Caixal À., Juan M., 1991, Resum de les conclusions de les investigacions històriques a l'església de Sant Vicenç de Malla, en A. Gonzáles, A. López Mullor (dirs.), Simposi A ctuacions en el patrimoni edificat medieval i modern (segles X al X VIII). I. La intervenció arquitectònica, II. La recerca arqueològica. B arcel ona, 5-7 d'octubre de 1989, Quaderns Científicis i Tècnics, Servei del Patrimoni Arquitectònic Local, Diputació de Barcelona, 3, pp. 183-192.

López Mullor A., Fierro J., En rich J. y J ., Sales J ., Beltrán DE HEREDIA J., (en prensa), Cerámica tardorromana y altomedieval en la provincia de Barcelona. Siglos VII-X, II Simposio de arqueología de M érida. C erámicas tardorromanas y altomedievales de la Península I bérica, CSIC, Consorcio de la ciudad monumental de Mérida.

López Mullor A., GonzÁlez A., 1991, N oticia sobre la segunda restauración de la iglesia de Sant Quirze de Pedret (Cercs, Barcel ona). La investigación preliminar, en A. Gonzáles, A. López Mullor (dirs.), Simposi A ctuacions en el patrimoni edificat medieval i modern (segles X al X VIII). I. La intervenció arquitectònica, II. La recerca arqueològica. B arcelona, 5-7 d'octubre de 1989, Quaderns Científicis i Tècnics, Servei del Patrimoni Arquitectònic Local, Diputació de Barcelona, 3 pp. 231-252.

López Mullor A., GutiérRez A., (en prensa), L'estudi arqueològic de I'antiga casa rectoral de Sant Andreu de Castellnou de Bages, Jornades d'A rqueologia de les Comarques de B arcelona, General itat de Catalunya, Servei d'A rqueologia.

López Mullor A., Sureda M. J., 1984, Església de Santa Càndia d'Orpí. N otícia històrica. Descripció de l'edifici. La recerca arqueològica, M emòria 1983, Servei de Catalogació i Conservació de Monuments de la Diputació de Barcelona. Barcelona, pp. 182-184, 187-191, 271-274.

MAETZKE G., RYSIEW SKA T., TABACZIN SKY S., ÚRBANEZYK P., 1977, Problemi dell'analisi descrittiva nelle ricerche sui siti archeologici pluristratificati, A rcheologia M edievale, IV, pp. 7-37.

N OLLA J.M., CASTAN YER P., TREM OLED A J., 1992, N uevos sistemas de registro: la experiencia de Vilauba, Ciencias, metodol ogía y técnicas aplicadas a la arqueol ogía, Barcelona, pp. 173-183.

PALLÀS C., 1962, A rte prerrománico catalán: Pedret y Obiols, San J orge, Barcelona, 47, pp. 63-67.

PARENTI R., 1985, La lettura stratigrafica delle murature in contesti archeologici e di restauro architettonico, R etauro e Città, I, n. 2, pp. 55-68.

PARENTI R., 1988a, Le techniche di documentazione per una lettura estratigrafica dell'elevato, en R. Fran covich, R. Parenti (a cura di), A rcheologia e restauro de monumenti, I ciclo di lezioni sulla ricerca applicata in A rcheologia, Certosa di Pontignano (Siena), 28 settembre 10 ottobre 1987, Firenze, pp. 249-279.

PARENTI R., 1988b, Sulle posibilità di datazione e di classificazione delle murature, en R. Fran COVICH, R. PARENTI (a cura di), A rcheol ogia e restauro dé monumenti, I ciclo di lezioni sulla ricerca applicata in A rcheologia, Certosa di Pontignano (Siena), 28 settembre-10 ottobre 1987, Firenze, pp. 280-304.

PARENTI R ., 1995, H istoria, importancia y aplicaciones del método de lectura de paramentos, $L$ er el documento construido $=$ Informes de la Construcción (Madrid), 46, n. 435, enero-febrero, pp. 19-30.

Ripoll E., SAn m ARTí E., López M ULlor A., 1982, Empúries, L'Escala, Les excavacions arqueològiques a Catalunya en els darrers anys, Excavacions Arqueològiques a Catalunya, 1, Servei d'Arqueologia, Generalitat de Catal unya, Barcelona, 1982, pp. 324-328.

R osSELL R., 1985, Cercs. Sant Quirze de Pedret. Pintures murals, Catalunya R omànica, X II. EI B erguedà, Barcelona, pp. 216-218.

TABALES M.A., 1998, A rqueología en edificios históricos de Sevilla. U na propuesta de intervención, Departamento de Prehistoria y Arqueología, Facultad de Geografía e H istoria, U niversidad de Sevilla, tesis doctoral inédita.

TROMBETTA P.J. 1986, El polémico proyecto del Louvre. Las excavaciones en la plaza cuadrada y en la plaza de $N$ apoleón, K oiné (Madrid).

TROMBETTA P.J . 1987, Sous la piramidedu L ouvre... 20 sièdes retrouvés, Paris. 